\title{
Resilience and mental health
}

\author{
Dmitry M. Davydov ${ }^{\text {a, c, * }}$ \\ Robert Stewart ${ }^{\mathrm{b}}$ \\ Karen Ritchie ${ }^{c, d}$ \\ Isabelle Chaudieu $^{\mathrm{c}}$
}

${ }^{a}$ Department of Neurophysiology, Moscow Research Centre of Narcology, 37-1

Lublinskaya ulitsa, Moscow, 109390, Russia. Email: d.m.davydov@ gmail.com ;

${ }^{\mathrm{b}}$ King's College London (Institute of Psychiatry), Section of Epidemiology (Box 60), De Crespigny Park, London SE5 8AF, UK. Phone +44 (0)20 7848 0136. Fax +44 (0)20 78485450. E-mail: Robert.Stewart@kcl.ac.uk ;

${ }^{\mathrm{c}}$ Institut National de la Santé et de la Recherche Médicale, U.888 Pathologies of the Nervous System: Epidemiological and Clinical Research, Hôpital La Colombière, 34093 Montpellier Cedex 5, France. Tel: 33 (04) 996145 60. Fax: 33 (04) 9961 45 79, E-mails: karen.ritchie@inserm.fr, isabelle.chaudieu@inserm.fr ;

${ }^{\mathrm{d}}$ Department of Neurosciences and Mental Health, Imperial College, London.

*Correspondence to Dmitry M. Davydov, INSERM, U888, Hôpital la Colombière, Pav.42 Calixte Cavalier, 39 av. Charles Flahault, BP 34493, 34093, Montpellier cedex 5, France. Email: d.m.davydov@gmail.com 


\begin{abstract}
The relationship between disease and good health has received relatively little attention in mental health. Resilience can be viewed as a defence mechanism, which enables people to thrive in the face of adversity and improving resilience may be an important target for treatment and prophylaxis. Though resilience is a widely-used concept, studies vary substantially in their definition, and measurement. Above all, there is no common underlying theoretical construct to this very heterogeneous research which makes the evaluation and comparison of findings extremely difficult. Furthermore, the varying multi-disciplinary approaches preclude metaanalysis, so that clarification of research in this area must proceed firstly by conceptual unification. We attempt to collate and classify the available research around a multi-level biopsychosocial model, theoretically and semiotically comparable to that used in describing the complex chain of events related to host resistance in infectious disease. Using this underlying construct we attempt to reorganize current knowledge around a unitary concept in order to clarify and indicate potential intervention points for increasing resilience and positive mental health.
\end{abstract}

Key words: psychological resilience; mental health; mental disorders; immunity model 


\section{Introduction}

The theoretical relationship between disorder and good health has been extensively discussed in relation to somatic health in terms of both treatment and prophylaxis (prevention, protection, and resistance); however, these issues have received substantially less attention in relation to mental health within both mono-causal (biomedical, psychological, or sociocultural) and multi-causal (biopsychosocial) models of psychopathology (Adler, 2009; Borrell-Carrió, Suchman, \& Epstein, 2004; Ghaemi, 2009; Kiesler, 1999). Although terminology relating to somatic disorders, such as trauma and stress, are now commonly used in mental health research and clinical practice, other positive concepts such as immune prophylaxis (Cooreman, Leroux-Roels, \& Paulij, 2001) and hygiene (Yazdanbakhsh, Kremsner, \& van Ree, 2002), although also potentially meaningful in relation to mental health, have not been considered. Only recently has the possibility of an immunity model been accepted in relation to mental well-being, but in terms of resilience (Bonanno, 2004), meaning more than simply the absence of disorder. Although this approach involves the identification of inherent and acquired clinical, biological and environmental characteristics which safe-guard mental health in the face of exposure to risk factors (Hoge, Austin, \& Pollack, 2007; Patel \& Goodman, 2007) until recently it has been conceptualized mainly in terms of mono-causal models, i.e., separately in biomedical, psychological, or sociocultural domains of resilience, without any attempt to integrate these within a general theoretical framework.

Mono-causal models of psychopathology continue to be popular in clinical practice due to their simplicity in terms of theoretical, therapeutic and disorder prevention approaches (e.g., purely a cognitive, behavioural, or emotion model in psychological assessment, psychotherapy research, teaching, and consultation), ignoring moderating, mediating and confounding effects of other biosocial variables. Mono-causal theories therefore may lose sight of the multi-causal nature of human health - from genes to cultures with developmental process mediating. Thus, we aimed to introduce a theoretical construct rather than eclecticism, for the integration of multiple 
mechanisms into a single framework applicable to any mental health problem (Norcross \& Goldfried, 2005). In this review we seek to demonstrate that the construct of mental resilience can provide a means of integrating social and natural sciences taking into account both psychosocial and biological models of mental health pathways.

While somatic disease, trauma and chronic stress are known to be common precedents of psychiatric disorder, epidemiological studies have found that in fact the majority of people who experience such stressful events do not develop psychopathology, raising the question of which resilience factors provide such mental 'immunity' (Patel \& Goodman, 2007; Collishaw, Pickles, Messer, Rutter, Shearer, \& Maughan, 2007; Jin, Tang, Ma, Lv, Bai, \& Zhang, 2009). Historically the general notion of protective factors for mental health dates back to the 19th century notion of mental hygiene defined as "the art of preserving the mind against all incidents and influences calculated to deteriorate its qualities, impair its energies, or derange its movements" and including "the management of the bodily powers in regard to exercise, rest, food, clothing and climate, the laws of breeding, the government of the passions, the sympathy with current emotions ..." (Rossi, 1962). Concepts of "mental immunity", "mental hygiene" or "mental resilience" have in common the aim of broadening research concepts in mental health beyond risk factors for pathology to include wellness enhancement and health promoting factors, in the same way that it has been important to identify the characteristics of infection-resistant groups during epidemics. Subsequently a number of studies have underlined the importance of good mental functioning (rather than the absence of disorder) in determining quality of life, cognitive capacity, physical health and social productivity (Huppert, 2005; Linley \& Joseph, 2004).

Our aim in this article is to review research on mental health protection, first considering the current concepts of mental resilience, then discussing mental health protection and resilience as integrating (multi-level biopsychosocial) constructs, comparing these with the semiotics and constructs of the somatic multi-level protection and immunity models. We demonstrate that the 
resilience concept in mental health research is currently hindered by the lack of a unified methodology and poor concept definition. Our underlying assumption has been that some other conceptual models such as multi-level protection, which have been developed for understanding resistance to some somatic disorders, might help the understanding of resilience to mental disorder. We attempt to compare some of the findings from, and definitions used, in mental resilience studies with the somatic immunity approach to consider whether mental health research can benefit from parallels in advances in the development of the 'immunity' framework. We do not propose that somatic immune and mental resilience systems are equivalent in low-level aspects of their relation to health disturbance. We consider 'immunity' as a general term for the state of being insusceptible or resistant to a specific threat to wellbeing, which was captured first by somatic medicine and by the legal system, but has been largely left unclaimed by mental health researchers. Theoretical construct of immunity in relation to somatic health has substantially evolved over time. Mental health scientists have on the other hand only recently accepted and extended the term 'resilience' as a theoretical construct of mental health protection, promotion and recovery processes; this term being originally used to describe the capacity of a material or system to return to equilibrium after a displacement. However, despite its metaphorical origin, resilience is now referred to in mental health science independently of its original context.

We propose that a comparison of two similar theoretical concepts of health protection (somatic 'immune' and mental 'resilience') will help to resolve two main challenges in mental health studies: (i) integration of different domains of the resilience construct (i.e. mental health protection, promotion and recovery) in one multi-level interacting system and (ii) merging theoretical models with an operational (resilience measurement) approach. So far, these theoretical and practical issues have been very poorly linked together and resilience has mainly been measured according to specific operational definitions depending on the aims of individual studies or according to predefined indicators relating to the theoretical position of an inventory's 
author (Kaufman, Cook, Arny, Jones, \& Pittinsky 1994; Vaishnavi, Connor, \& Davidson, 2007). These hamper meta-analysis of findings across resilience studies and challenges in resilience research may be principally explained by defects in operationalisation stemming from the absence of a common theoretical model. We consider that extrapolation from a somatic immunity approach to mental health is in accordance with George Engel's biopsychosocial model of health in general without the distinctions it draws between somatic and mental domains (Ghaemi, 2009). In a practical sense the immunity model proposes that each level of resilience can be employed to protect an individual's mental health more or less effectively depending on the condition in question, analogous to pluralistic models in psychiatry like Jaspers' methodological pluralism (Ghaemi, 2007) and Adler's approach of high and low system levels integration in biopsychosocial models (Adler, 2009).

In this review we also i) explore potential biological, behavioural and social mechanisms conferring resilience, ii) classify resilience research both by levels (individual and group) and by approaches (harm-reduction, health protection and promotion), iii) critically examine measurements of resilience, iv) offer a group of adaptive reactivity indicators as common measures of resilience affected at different levels and by different mechanisms, and v) suggest some challenges for future resilience research. Our general aim is to advance theoretical conceptualizations of resilience towards the resolution of conceptual inconsistency and hence facilitate its measurement.

\section{Current conceptualisations of resilience}

The now widely-used concept of resilience, derived from both the social and health sciences (Tusaie \& Dyer, 2004) has often been criticized (Luthar, Cicchetti, \& Becker, 2000; VanderbiltAdriance \& Shaw, 2008; Earvolino-Ramirez, 2007) due to ambiguities in both definitions and terminology, heterogeneity in the level and type (e.g. 'personal meaning') of risk or stress experienced for someone to be termed 'resilient' and in the competence required by individuals in 
order to be qualified as such. Together these criticisms have cast doubt on the utility of resilience as a theoretical construct. For example, some researchers have investigated resilience (or 'resiliency') as an individual trait (Ong, Bergeman, Bisconti, \& Wallace, 2006) or an epiphenomenon of adaptive temperament (Wachs, 2006). In some studies (Fredrickson, Tugade, Waugh, \& Larkin, 2003) habitual effective coping as a durable personal resource is considered to constitute a facet of trait resilience, which functions as a reserve that can be drawn on as a buffer against a wide range of future adversities. Positive emotions are seen as active ingredients within trait resilience, which reduce the risk of depression and promote thriving (Fredrickson et al., 2003). In other studies, emotional resilience has been used as a concept to imply the flexible use of emotional resources for adapting to adversity (Waugh, Fredrickson, \& Taylor, 2008) or as the process linking resources (adaptive capacities) to outcomes (adaptation) (Norris, Stevens, Pfefferbaum, Wyche, \& Pfefferbaum, 2008). Researchers using this concept view resilience as a process or force that drives a person to grow through adversity and disruption (Jacelon, 1997; Richardson \& Waite, 2002; Richardson, 2002). The resilience may vary according to age (e.g. suggested to decrease over 70 years, Rothermund \& Brandtstädter, 2003), with modifications occurring throughout the lifespan at both individual and cultural levels (Hegney et al., 2007; Gillespie, Chaboyer, \& Wallis, 2007; Connor \& Zhang, 2006). Overall these definitions are ambiguous and difficult to operationalise for measurement purposes.

On the other hand the numerous studies of determinants of resilience have been quite specific (Connor \& Zhang, 2006; Cameron, Ungar, \& Liebenberg, 2007; Norris et al., 2008) including genetic, biological, psychological, family, community, social, and environmental effects, which may interact during exposure to particular environmental hazards. Resilience has been investigated as a function of environmentally determined individual development (e.g. social or ethnic group) and also as a result of genetic factors (Cameron et al., 2007). For example, shared family and unique environmental effects have been reported to account for the variance in perceived severity of daily stressors (Charles \& Almeida, 2007) which is in turn a determinant of 
resilience (Stawski, Sliwinski, Almeida, \& Smyth, 2008). In addition, the influence of a unique environment on perceived stress has been observed to exert a stronger influence on older adults irrespective of gender (Charles \& Almeida, 2007). Gender has, however, been observed to modulate genetic effects. For example, a meta-analysis relating to brain-derived neurotrophic factor (BDNF) Val66Met polymorphism found significant resilient (protective) effects against depression in men, but not in women (Verhagen et al., in press).

A range of studies have suggested that 'resilience' can be seen as synonymous with reduced 'vulnerability' (Hofer, 2006; Schneiderman, Ironson, \& Siegel, 2005), with ability to adapt to adversity (Stanton, Revenson, \& Tennen, 2007; Kim-Cohen, 2007; Cameron et al., 2007) or 'cope’ (Taylor \& Stanton, 2007; Skinner \& Zimmer-Gembeck, 2007). Such studies implicate various adaptive systems as explanations of resilience, focusing on processes acting at multiple levels from childhood to old age, which promote and protect human development across the life span (Masten \& Obradovic, 2006; Lerner, 2006; Carrey \& Ungar, 2007).

At a conceptual level it is important to distinguish mechanisms: (i) against aversive or stressful events themselves (often defined as a resistance), (ii) against adverse outcome in terms of transformation of adaptive responses and health promotion processes to maladaptive (defective) ones (i.e., persistent dysfunction), and (iii) against development of a disorder (psychopathology) in the face of aversive events. The first domain of resilience may be defined as non-adaptive types of protection at an individual level due to resources (adaptive capacities) taken from external levels (e.g., society) and may be attributed to the mental health protection system (Figure 1 and Table 1). The last two domains of resilience may belong to the same dimension (the adaptive type of protection of a person), but may be explored from different perspectives on human health and its disturbance and may be attributed to the mental health resilience system itself (Figure 1 and Table 1). According to one definition, the healthy condition is related to the development of a phenotype of reactivity to environmental challenges which may be adaptive or maladaptive 
depending on the context (Ellis \& Boyce, 2008), but may also be viewed in terms of the traditional nosological or biomedical conception of health.

Thus, understanding resilience is important as a means of developing interventions to prevent and/or treat common mental disorders whose risk factors have high individual and cultural variability in impact, notably anxiety, depression, and stress reactions (Connor \& Zhang, 2006). However, although the mental health protection approach has benefited from empirical research, potential deficiencies in its central terminology have inhibited further conceptual development. A broad systems approach, inferring the capacity of dynamic systems to withstand or recover from significant disturbance (Masten, 2007) has more recently been proposed as being potentially more relevant. Such a biopsychosocial model of resilience assumes the existence of multiple processes within and outside an organism protecting against disturbance in a manner similar to the complex model of somatic health protection system.

\section{A biopsychosocial (multi-level) construct for mental resilience}

This approach assumes firstly that, in order to survive a psychological challenge, the system should have in-built mechanisms able to recognize and neutralize adversities and their related effects. As with somatic immunity against a specific pathogen, these resilience mechanisms may be innate, or may have been developed: naturally through individual adaptation, or artificially through external influences such as public health activities (Tables 1 and 2). The mechanisms may engage individual resources actively or passively, may be independent with respect to each other, may interact, or may constitute a causal chain (see Figure 1). They may serve to protect and/or promote mental health, accelerate recovery and/or mitigate the negative effects of mental 'pathogens' - i.e. stressors (see Figure 2). This approach refers to i) 'harm-reduction' factors which can operate in the face of risk factors which may themselves be difficult to modify (such as genetic risk factors or poverty); ii) protective factors which decrease the probability of pathology, 
and iii) promotion factors which actively enhance positive psychological well-being (Hoge et al., 2007; Patel \& Goodman, 2007).

Through evolution, biological organisms have developed various adaptive and defensive systems to survive and cope successfully with stressors. According to the 'law of parsimony' a general operational principle is that these systems should be similar. For example, analogous to somatic health protection (e.g., the somatic immune and hygiene systems), the mental resilience system is likely to protect against adversities through multi-level defence mechanisms of varying specificity in terms of the stressor and/or subject in question (see Table 1). Non-specific mechanisms may include, for example, geographical, political, economic, social, medical and cultural barriers modifying the effects of a variety of risk factors such as bereavement, disability, unemployment, and poverty. Breaching these barriers (e.g., see discussion below relating to the collapse of the Soviet Union, Nepomnyashchiy \& Davydov, 2007) may give rise in turn to an immediate nonspecific defence response by the individual, either withdrawal (freeze - isolation or flight immigration, escape), or engagement (fight - strike, attack) depending on individual physiological arousal conditions (Davydov, Shapiro, Goldstein, \& Chicz-DeMet, 2005; Davydov, Shapiro, Goldstein, \& Chicz-DeMet, 2007a). Adversity penetrating this non-specific individual defence barrier may generate a third level of reactivity at an individual level (e.g., different avoidance and approach coping strategies). If successful this specific (adaptive) response is retained in individual memory (as a process of 'behavioural immunization', Seligman \& Maier, 1967) allowing the resilience system to mount faster and stronger attacks next time this specific adversity is encountered. The effectiveness of both non-specific and adaptive (specific) resilience barriers depends on the ability of the system to distinguish between adversities and advantages at both a group and individual level. As with promotion approaches for improving somatic health (e.g. prophylactic immunization) the model assumes multiple levels of adjustment combining external (passive immunization) and internal (active immunization) resources to enhance mental health in advance against possible future adversities (see Tables 1 and 2). 
However, within a somatic immune system some normal defence strategies (such as inflammation) may themselves become handicapping (e.g., hypersensitivity or auto-immunity). In the case of mental health, this might involve outcomes such as dependence on external rewards (e.g. financial support from the state), phobias or physiological vulnerability (e.g. chronically raised cortisol levels). Other examples of such trade-offs in somatic health are protection mechanisms such as fever, diarrhoea and vomiting, which can be considered as normal defences but which may become themselves the source of health disturbance if they are not sufficiently controlled. Another example of trade-off in relation to mental health is national borders, a resilience (external protection) factor provided by society (see above and in Tables 1 and 2). Borders may constitute a resilience factor both by providing protection from external challenges or outflow of the nation's own protective benefits. However, borders and their associated laws may also constitute an impediment for some persons (migrants, refugees or asylum seekers) escaping threats in their own country and in the context of persons and societies seeking the import of advanced ideas, creations, technologies, people and goods for sustained development. Moreover, for some groups of people (e.g., for quasi-nomadic people such as some businessmen, scientists or artists whose activities demand sharing of finance, knowledge and products of their creativity, for people with risk- or sensation-seeking phenotype or for people living in traditional nomadic cultures) the ability to cross borders constitutes an important on-going resilience factor against threats for their well-being. For these persons border permeability may reduce threat. Some trade-off controversies and defects in the somatic protection and mental resilience systems associated with their dependence on context in transformation to risk factors may have common external (e.g., cultural) or internal (genetic, Suchankova, Henningsson, Baghaei, Rosmond, Holm, \& Ekman, 2009) determinants. Thus, potential adverse effects of a resilience system should also be considered. Subsequently most of the resilience factors summarized in Tables 1 and 2, Figure 1 and elsewhere in the text should also be considered in terms of their context (i.e., dependence 
on 'quality' or presentation of other biopsychosocial resilience or risk factors) with a possible trade-off between their resilience and risk effects on mental health.

Individual level of resilience: Individual-level resilience requires individual non-specific and specific-to-adversity 'natural immune' resources to confer resilience (see Tables 1 and 2, Figure 1). These mechanisms are the focus of studies of why some individuals who are exposed to known risk factors, do not develop mental health problems. This approach has provided insights into resilience in the same way that somatic studies have investigated commercial sex workers who have not contracted HIV/AIDS (Rowland-Jones et al., 1998; Kaul, Plummer, Kimani, Dong, Kiama, \& Rostron, 2000), or cancer survivors who have exceeded their life expectancies (Gotay, Isaacs, \& Pagano, 2004). In the mental health domain such 'high-exposure' studies have included patients awaiting cardiac surgery with resilience to anxiety-related heart rate hyperactivation (Bokeriia, Golukhova, Polunina, Davydov, \& Kruglova, 2008), people after bereavement with resilience to chronic grief (Bonanno et al., 2002), and other examples of individuals retaining a positive outlook in difficult circumstances (Felten \& Hall, 2001; Windle, Markland \& Woods, 2008; Jones, 2006; Becoña, 2007). Some individuals have been shown to benefit from resiliencepromoting interventions such as stress-management and stress-prevention (Steinhardt \& Dolbier, 2008). Moreover, aspects of mental health resilience (such as positive affect, positive expectancy regarding health outcomes, finding meaning in challenging circumstances) may also assist in maintaining somatic well-being (Ickovics, Milan, Boland, Schoenbaum, Schuman, \& Vlahov, 2006). Some somatic immune mechanisms (e.g., cytokines) may have a direct promoting influence on internal mental resilience barriers (Miller, 2009; Goldstein, Kemp, Soczynska, \& McIntyre, 2009). The adaptive somatic immune system involving immunological memory to selfantigens (e.g. memory T-cells to CNS-related antigens) has been suggested to be involved in the so-called 'behavioural immunization' mechanism of mental resilience (Lewitus \& Schwartz, 2008). Moreover, immunization with CNS-related antigens as a means of protecting against depression has recently been introduced (Lewitus et al., 2009). 
Group level of resilience: Group-level factors can be imposed on an individual by external resources (geographical, national, cultural, community or social) analogous to social hygiene or herd immunity in somatic health (see Tables 1 and 2, Figure 1). For example, folic acid fortification of all enriched grain products in the United States, an intervention at a national level to reduce the risk of neural tube birth defects in newborns, has been suggested to have an additional effect of improving and promoting mood because higher serum folate levels are associated with better mood in at-risk groups and may play a protective role against depression among specifically predisposed individuals (Alpert, Mischoulon, Nierenberg, \& Fava, 2000). Another proposed example are omega-3 fatty acid fortification programs, which may have both harm-reduction and health promotion effects for mental health (Freeman et al., 2006; Hibbeln, Ferguson \& Blasbalg, 2006; Harris, 2007; Lin \& Su, 2007; McNamara et al., 2009). Some advantages of group-level protective factors have been received by individuals through education and employment laws which for example protect children from child labour, and which have the potential to be further developed if schools and local communities become able to screen for abuse. However, some group factors favouring protection against some challenges may be detrimental for others. For example, lipid-lowering recommendations in many Western countries protecting against cardiovascular diseases has been suggested to inactivate a biological component of the resilience system against adverse psychological and behavioural problems in some persons (Troisi, 2009).

The group factors may account, at least in part, for variations in prevalence of mental disorders between different populations: for example between countries or between migrant and nonmigrant groups. For example, two population-based surveys in Great Britain found a 3-fold lower prevalence of child mental disorder among populations of Indian origin (Green, McGinnity, Meltzer, Ford, \& Goodman, 2005; Meltzer, Gatward, Goodman, \& Ford, 2000), raising the possibility of a group-level resilience mechanism in the context of an overall decline in child 
mental health in Britain in recent years (Collishaw, Maughan, Goodman, \& Pickles, 2004; Rutter \& Smith, 1995). Another related finding is a relatively low rate of suicide in older men of South Asian ancestry in Britain (England and Wales) and across the world compared to peers of other origins (McKenzie, Bhui, Nanchahal, \& Blizard, 2008). Furthermore, the World Mental Health Survey found some of the lowest prevalences of disorder in some of the poorest and most disadvantaged populations in the world - populations in which well-established individual-level risk factors such as acute economic difficulties, poor housing and low education are widespread (Demyttenaere et al., 2004). Several authors have stressed the need for resilience research to include ecological analyses as there is likely to be variability in the effects of individual-level resilience factors between different populations and cultures (Haeffel \& Grigorenko, 2007; Diener, Oishi, \& Lucas, 2003). However, a substantial challenge is of course the wide variety of cultural and linguistic differences in conceptions and meanings of mental health. Another challenge is to distinguish whether a particular group-level effect is related to a specific cultural factor or social context (externally provided for individuals), or to a genetic resilience resource (internally retrieved by individuals) in ethnically homogeneous groups (Voracek \& Loibl, 2008; Wiltermuth \& Heath, 2009; McCormick, Frey, Lee, Gajic, Stamatovic-Gajic, \& Maksimovic, 2009): for example Japanese women experiencing relatively few physical and emotional symptoms in the peri-menopausal period (Steiner, Dunn, \& Born, 2003). It has thus been proposed that these findings may not only indicate cultural differences but also may reflect the influence of biological, genetic and nutritional/dietary factors (Lock, 1994; Nagata, Takatsuka, Inaba, Kawakami, \& Shimizu, 1998).

\section{Resilience approaches in mental health research}

The harm-reduction approach (Figure 2): Some researchers describe mental resilience in terms of quick and effective recovery after stress (Tugade \& Fredrickson, 2004). This parallels somatic recovery mechanisms after pathogen invasion through external and internal protective barriers, and describes the ability to 'spring back' to initial levels of mental, emotional and cognitive 
activity after an adversity (such as functional limitation, bereavement, marital separation, or poverty). The 'pathogen invasion' construct implies that both cognitive appraisal of an event and the emotions induced by the event are perceived by the individual as negative or stressful (Davydov, Zech, \& Luminet, 2008), i.e., an event acquires a personal meaning, which can be semiotically designated as a sign (Adler, 2009). In some cases this aspect of resilience is operationalised as a general health score that, despite deterioration after exposure to adversity, subsequently returns to pre-exposure levels. The prevalence of this kind of resilience has been estimated in community studies to be about $15 \%$ : highest in older women and increased by 40 $60 \%$ in the presence of high social support before and during adversity (Netuveli, Wiggins, Montgomery, Hildon, \& Blane, 2008). Other researchers argue that harm-reduction or recovery mechanisms of resilience should be distinguished from mechanisms of protection or resistance against harmful effects of adversity, which may be associated with different underlying neurobiological processes (Yehuda \& Flory, 2007).

The protection approach (Figure 2): In other studies, mental resilience is described in terms of protection mechanisms (analogous to 'immune barriers'), which help to preserve a given measure of health in the face of adversity (Patel \& Goodman, 2007). For example, in a national community study of adults with chronic pain using the Profile of Chronic Pain Screen, a subsample with this kind of resilience was identified who had high scores (at least 1 SD above the mean) on a severity scale combined with low scores (at least 1 SD below the mean) on scales assessing interference and emotional burden (Karoly \& Ruehlman, 2006). An age- and gendermatched non-resilient sub-sample was then selected with high scores (at least 1 SD above the mean) on all three scales. Different specific factors may be related to this type of resilience at multiple (e.g., individual and group: family, peer group, school and neighbourhood) levels (Jessor, Turbin, \& Costa, 2003). For instance, in two epidemiological studies resilience in adults who had experienced early adversity was associated with higher quality of interpersonal 
relationships in adolescence and adulthood (Collishaw et al., 2007; Quinton, Rutter, \& Liddle, 1984; Rutter \& Quinton, 1984).

The promotion approach (Figure 2): Some researchers have associated the concept of resilience with promotion of mental health (Ong et al., 2006; Patel \& Goodman, 2007). This approach focuses on the development of additional resources, which can be used (applied for) by harmreduction and protection mechanisms (analogous to pre-immunization or a general strengthening of the immune system), but has been mainly associated with high individual levels of positive experience (Fredrickson, 2004; Fredrickson \& Joiner, 2002). For example, the Isle of Wight study found that the maintenance of mental health in adulthood despite substantially higher levels of psychosocial stressors (e.g. criminality and worse relationship quality) could be explained by the absence of early physical or sexual abuse, which was hypothesized to promote in turn positive psychological well-being as a resilient barrier against later adversity (Collishaw et al., 2007). A meta-analysis concluded that the occurrence of daily positive emotions serves to moderate stress reactivity and mediate stress recovery and that differences in this kind of psychological resilience account for meaningful variation in daily emotional responses to stress (Ong et al., 2006). Higher levels of this kind of resilience predict a weaker association between positive and negative emotions, particularly on days characterized by heightened stress. Over time, the experience of positive emotions functions to assist high-resilience individuals in their ability to recover effectively from daily stress. This type of resilience mechanism is not restricted to the individual level but can also be considered to be the result of a variety of external (e.g., community and cultural) factors. Indeed, some social resilience mechanisms such as religion are commonly associated with positive emotions.

However, in studies of mental health promotion, the 'positive experience' mechanism underlying anti-stress fortification (i.e. presence of fewer adversities in past and/or more positive events) can be contrasted to a 'behavioural immunization' (analogous to vaccination) mechanism underlying 
anti-stress training (i.e. relating to memory of past negative experience). In contrast to "positive experience', 'behavioural immunization or immunomodulation' promotes mental resilience through exposure to a transitory stressful event, which is successfully overcome; this exposure may be delivered to a person either naturally (i.e. during everyday life) or artificially (e.g. by a behavioural training programme) (see Tables 1 and 2). For example, experienced survivors of floods were found to exhibit lower anxiety after encounters with the same disaster compared with inexperienced survivors (Norris \& Murrell, 1988). These two mechanisms may promote resilience differently: (i) by increasing protection in a manner which is not specific to the index stressor (indexed by a reactivity capacity) or (ii) by increase of a stressor-specific protection indexed by a wider number of specific stressors (see discussion below and Figure 2).

In the psychology of positive mental states, this 'anti-stress training' phenomenon has been contrasted to a process of simple recovery or the return to prior (pre-trauma) baseline states (i.e., homeostasis) and described as thriving or 'going beyond the previous baseline to grow and even flourish' (Joseph \& Linley, 2006, p. 1043). This theory proposes that simple recovery after stress still leaves a person at increased vulnerability to a similar adversity. However, underlying mechanisms and instruments for assessing such phenomena as 'thriving' and reorganization of functioning have not been well-characterised (Frazier, Tennen, Gavian, Park, Tomich, \& Tashiro, 2009). The 'behavioural immunization' approach on the other hand proposes that positive changes following adversity are related to a return from mental disorganization to a healthy baseline (homeostasis), with resilience conferred by new positively accommodated experience (memory). This new experience results in a more flexible regulation system for maintaining homeostasis and mentally healthy functioning within a wider range of stressful events (i.e. resistance to more 'strains' of mental 'pathogens') compared to the pre-trauma period (Figure 2). This extension of 'living space' associated with mentally healthy functioning or mental resilience is therefore the result of adverse experiences, which a person after adversity may benefit from and 
which can be assessed in everyday life by psychophysiological instruments (see, e.g., Davydov, Shapiro, \& Goldstein, 2010).

As with somatic immunity these two promotion mechanisms (anti-stress fortification and training) may have dose-response relationships in terms of conferring resilience. For example, living in a psychologically sterile environment (absence of any past adversity) can result in reduced individual resilience to even moderate stressful events because of decreased tolerance (analogous to theories of hypersensitive immune responses). On the other hand, an extremely stressful experience (unresolved or chronic stress) can also lead to poor individual resilience to future adversities through increased tolerance (analogous to immune deficit hyposensitivity mechanisms). Taken together, these theories propose that effective mental resilience requires an individual homeostatic balance between negative and positive experiences, just as immune activation and suppression are proposed to balance in the modern hygiene hypothesis (Yazdanbakhsh et al., 2002; this is discussed further under challenge 1). This approach has been elaborated under a framework of the homeostatic hypothesis of emotion regulation by a general arousal manipulation (Davydov, Lavrova, \& Drozdov, 2005; Davydov, Shapiro, et al., 2005; Davydov et al., 2007a). The homeostatic concept hypothesizes that a balance between negative and positive experience in everyday life is essential for mental health in the individual, and may be maintained by different circadian physiological mechanisms regulated through baroreflex pathways (Davydov et al., 2010).

\section{Some potential multi-level mechanisms conferring resilience}

\section{Genetic, Epigenetic and Gene-environment mechanisms}

The individual- and group-level approaches include the relevance of gene-environment interactions to resilience against mental disorders. Gene-environment interactions involving exogenous and endogenous environmental factors are known to shape behaviour and personality development (Schmidt, Fox, Perez-Edgar, Hamer, 2009). The genetic effects are now thought to 
influence person-environment interactions (reactivity phenotypes) rather than rigidly define psychopathological phenotypes (Wichers et al., 2007a).

Meta-analyses of gene-environment interactions (Munafò, Durrant, Lewis, \& Flint, 2009) suggest that deficient knowledge of the type of interaction between specific genes and specific challenges (e.g. synergism, antagonism, and crossover) limits understanding of how a given interaction operates with respect to a specific reactivity phenotype in particular context (i.e. whether adaptive or maladaptive). For example, human fMRI studies suggest associations between the 5hydroxytryptamine transporter-linked promoter region (5-HTTLPR) $s$ allele and both higher baseline activity and lower relative reactivity to neutral stimuli in the amygdala, which in turn may be associated with poor anterior cingulate control found in subjects with harm avoidance traits (Munafò, Brown, \& Hariri, 2008; Pezawas et al., 2005; Uher \& McGuffin, 2008). High harm avoidance reflects a tendency to avoid new situations and aversive stimuli (i.e. inhibition of behaviour), which may be associated with lower tolerance to (i.e., lower resilience in) a noveltyrich environment (higher negative affect), but with higher tolerance to (higher resilience in) novelty-poor environment (higher positive affect) (Davydov et al., 2007a). These observations raise the possibility that a specific reactivity or arousal phenotype can be adaptive and confer resilience (i.e. protective effects) in some conditions, but may be maladaptive and harmful (i.e. exert risk effects) in others.

Thus, in most cases, presence of a specific factor (e.g. a reactivity phenotype) may be a necessary component of resilience, but the effect may be stronger, weaker or even reversed depending on additional contributory factors (e.g. specific environmental contexts at various stages of human development distal or proximal to time of manifestation). Thus, due to evolutionary-determined genetic polymorphism, any environmental context (from high ecological stress and instability to stable and predictable ecology) could 'meet', 'select', 'shape', 'regulate' or 'build' its own most adaptive endophenotype with a specific balance maintained with respect to inhibiting or 
activating neurobiological effects (Ellis, Jackson, \& Boyce, 2006; Chiao \& Blizinsky, 2010; illustrated as forward effects in Figure 1). In turn, individual differences in reactivity phenotype may help a species as a whole to survive with competing life functions of growth, maintenance, and reproduction in a complex and fluctuating environment. However, in the human world, groups of individuals with some specific reactivity phenotypes can 'select', 'shape', 'develop', 'regulate', 'defend', 'sustain' or 'build' societies with specific rules and laws (illustrated as backward effects in Figure 1) favouring resilience in some groups but being detrimental to others, and thus overall less advantageous for the human species as a whole (see related discussion in more details below).

Indeed, previous studies suggest that the same gene or environment may confer resilience (e.g., mental health promotion) or risk depending on a state of associated components with respect to a specific gene-environment interaction (e.g., Bakermans-Kranenburg \& van Ijzendoorn, 2007; Belsky, Jonassaint, Pluess, Stanton, Brummett, Williams, in press; Schmidt et al., 2009). It has been proposed that the genes, which render individuals disproportionately vulnerable to adversity (e.g. heightened stress reactivity), simultaneously confer on them an advantage in terms of increased benefit from environmental support or enrichment (Ellis \& Boyce, 2008). This approach views possible 'vulnerability genes' or 'risk alleles' as 'plasticity genes', proposing that they increase susceptibility to both positive and negative environmental conditions, i.e., to environmental influences both for better and for worse (Belsky et al., in press). This 'differentialsusceptibility' or 'developmental plasticity' hypothesis argues that specific genetic or environmental conditions are not predefined simply as either risk or resilience factors, but may determine both risk and resilience in different gene-environment combinations. This parallels the view of some immune system characteristics as both potential risk (disease-conferring autoimmune response) and resilience factors (health-protective immune response) depending on different exo- or endogenous environmental conditions. For example, the long allele of the dopamine D4 receptor gene (DRD4) has been found to predict positive follow-up outcomes (e.g. 
positive affective condition, higher levels of attachment security, lower levels of externalizing problem behaviour) compared to those with the DRD4 short allele if associated with left frontal asymmetry in resting brain activity (favourable endo-environment, Schmidt et al., 2009) or with absence of mothers' unresolved loss status and high quality of sensitive parenting (favourable exo-environment, Bakermans-Kranenburg \& van Ijzendoorn, 2007). However, presence of the same DRD4 long allele was found to predict negative outcomes (cognitive difficulties, attachment disorganization, externalizing problem behaviours) compared to the DRD4 short allele if it was coupled with right frontal asymmetry of resting brain activity (unfavourable endo-environment) or with mothers' unresolved loss status, insensitive parenting (unfavourable exo-environment). Favourable and unfavourable endo- and exo-environment did not influence outcome in the absence of the DRD4 long allele.

Other meta-analytic and prospective population studies of the 5-HTTLPR $s / l$ SNP suggest that specific adversity-related exoenvironments during childhood (e.g. emotional sharing of parental problems) as vulnerability factors for lifetime depression may be enhanced by the $l$ allele but, during childhood and adulthood, other types of adversities (e.g. suffering from aggressive acts) may be enhanced by the $s$ allele (Brown \& Harris, 2008; Kaufman et al., 2004; Ritchie et al., 2009; Uher \& McGuffin, 2008). Since different periods of life have different ratios of events appraised as positive and negative, a given 5-HTTLPR allele determining a general sensitivity to the environment may confer either mental resilience or vulnerability depending on the balance of particular positive and negative events for a given life stage. Positive experiences may 'undo' (i.e., mitigate) or even reverse (i.e., down-regulate) the physiological arousal ('cost') associated with negative feelings and further moderate genetic sensitivity to stress (Davydov et al., 2008; Fredrickson \& Levenson, 1998; Shapiro, Jamner, Goldstein, \& Delfino, 2001; Wichers et al., 2007b; Wichers et al., 2008a). If a person lives in a relatively positive environment (e.g. with close, confiding relationships) they may benefit from the 5-HTTLPR $s$ allele as a resilience factor associated with a higher sensitivity phenotype (a health promotion mechanism); however, a 
person living in a relatively negative environment may benefit from the $l$ allele as a resilience factor associated with a lower sensitivity (higher tolerance to aversive events) phenotype (a health protection mechanism). Thus, the phenotypic dimension related to reactivity (endo-environment) should be always evaluated against an exo-environment to consider as resilience or risk factor in specific condition. As a further example, women with a high arousal phenotype (high stress hormone activity) feel well during the follicular phase of menstrual cycle, but feel less comfortable during the luteal phase (Davydov et al., 2007a). However, women with low arousal phenotype (low stress hormone activity) may benefit from a stressful environment (hard work, sport activity) during the follicular phase of menstrual cycle in contrast to women with a high arousal phenotype. Alexithymia phenotypes constitute another example (described below).

The gene-environment interactions discussed earlier may be called either synergistic (interaction of individual and group resilience factors as health promotion mechanism) or reciprocal (interaction of resilience and risk factors from different levels as health protection mechanism). A synergistic interaction of individual and group resilience factors was found, for example, in children with a highly reactive phenotype (i.e. sensitive to environmental processes) living in a supportive social context that produced relatively high levels of cognitive and social competence in this group (Ellis \& Boyce, 2008). Two reciprocal gene-environment approaches may be defined: i) particular gene alleles conferring protection against the negative effects of life stressors in some conditions (Uher \& McGuffin, 2008; Feder, Nestler, \& Charney, 2009) and ii) risk associated with particular genetic factors modified by the environment for particular outcomes (Freedman, 2008; Ritchie et al., 2009). Examples include the study cited earlier of the BDNF Val66Met polymorphism protecting against major depressive disorder in men (Verhagen et al., in press), and modification by ethnic group of the associations between KIAA0319 dyslexia susceptibility gene polymorphisms and reading difficulties in children (Paracchini et al., 2008). In the latter case it has been postulated that one of the resilience factors modifying genetic influence may be parental education (Friend, DeFries, \& Olson, 2008). Analysis of positive 
associations between depression and the apolipoprotein E epsilon 4 allele has suggested that men may have resilience against this potential risk factor (Müller-Thomsen et al., 2002) which may include pathways such as capacity for intensive aerobic activity (Russo-Neustadt, Ha, Ramirez, \& Kesslak, 2001; Southwick, Vythilingam, \& Charney, 2005). Other studies have suggested that the majority of people who have genetic variants associated with higher risk of psychopathology may obtain or develop bio- and psycho-social resilience (Freedman, 2008). However, interpretation of many gene-environment interactions depends on analytical approaches and demands further replication.

Gene-environment interactions can be also modulated by change in endogenous environment associated with other genes and their respective interactions with exo-environment or by change in appraisals of values of events. This conclusion is in accordance with recent experimental and meta-analytic studies suggesting that some polymorphisms may not directly modulate vulnerability to depression, but may be components in the modulation of more general behaviour phenotypes via complex interactions of endoenvironments or endophenotypes (gene-gene interactions) with positive and negative exoenvironments (Feder et al., 2009; Kaufman et al., 2006; Uher \& McGuffin, 2008; Wichers et al., 2008b). Moreover, the genome may be programmed by epigenetic mechanisms driven by interactions between an individual and their environment over their lifespan (Szyf, McGowan, \& Meaney, 2007). These epigenetic mechanisms may contribute to individual resilience (Nestler, 2009; Feder et al., 2009) and to the inheritance of acquired resilience mechanisms in offspring (Harper, 2005). Epigenetic mechanisms provide a potential pathway through which environmental or group-level resilience factors can modify individual responsiveness to stress. Through this pathway, behavioural responses to environmental stresses may generate changes in gene expression due to cellular epigenetic changes influencing, for example, the likelihood of point mutation, transposition, recombination, and other genomic reorganizational processes (Jablonka, 2007). Thus, epigenetic modifications of gene expression viewed as responses to environments to which the developing, 
matured and/or aging brain are exposed (Akbarian \& Huangm, 2009; Sweatt, 2009) could help explain at least some ethnic, age and gender differences in protection against mental disorders. Recent observations are compatible with such epigenetic explanations including findings of stress-related gene expression and the relevance of childhood adversity to the development of future stress reactivity (Yehuda \& Bierer, 2009). The association between specific gene polymorphism and epigenetic modifications with further contributions from different exogenous risk and resilience factors during different life periods may produce an integrated phenotype of reactivity (Wichers et al., 2009), which is adapted to some conditions, but maladaptive to others. Thus, research into gene-environment and gene-gene interactions allowing for epigenetic modulation is a complicated issue and meta-analysis is often less able to reveal these interactions than single studies. These results should thus be interpreted with caution. Moreover researchers should be cautious in not adopting an over-deterministic view with regard to genetic effects, because, as discussed above, interaction between genes themselves as much as between single genes and the exo- and endo-environment is likely to be key to resilient phenotypes (illustrated as interaction effects in Figure 1).

\section{$\underline{\text { Behavioural and associated neuronal mechanisms }}$}

Factors, which are believed to be potentially important as resilience-related in either beneficial (synergistic interaction for health promotion) or aversive (reciprocal interaction for health protection) conditions include the following behavioural mechanisms: i) aspects of intellectual functioning and cognitive flexibility (positive explanatory style, reappraisal and acceptance), ii) social attachment and social behaviours such as altruism, iii) positive self-concept and effective self-regulation of emotions, iv) positive emotions including optimism and humour, v) capacity to convert traumatic helplessness into learned helpfulness, vi) meaning including religion/spirituality, vii) social support including role models, viii) active coping style in confronting a stressor including exercise and training, ix) capacity to recover from negative 
events and stress inoculation, $\mathrm{x}$ ) capacity to accommodate the new trauma-related information in a positive direction (Joseph \& Linley, 2006; Charney, 2004; Southwick et al., 2005).

These behavioural mechanisms may, at least in part, be mediated through neurobiological factors of potential interest in relation to resilience in contexts of specific internal and external environments: oxytocin, prolactin, dehydroepiandrosterone (DHEA), corticotropin-releasing hormone (CRH) effects on $\mathrm{CRH}-2$ receptors, neuropeptide $\mathrm{Y}$, galanin, brain-derived neurotrophic factor (BDNF), GABA-benzodiazepine receptors, serotonin effects on the 5-HT1A receptors, and testosterone (Charney, 2004; Feder et al., 2009; Heinrichs \& Koob, 2004; Slattery \& Neumann, 2008, Southwick et al., 2005). Underlying neurobiological processes can also be described neuroanatomically with particular regions of interest including the medial prefrontal cortex, anterior cingulate, nucleus accumbens, amygdala, hippocampus, ventral tegmental area, and hypothalamus (Feder et al., 2009). Neuronal mechanisms (neural circuits) potentially underlying resilience to stress and psychopathology might include regulation of reward, social emotions (e.g., shame, guilt, empathy) and emotions in general, motivation (hedonia, optimism, and learned helpfulness), reconsolidation, Pavlovian (cue specific) fear conditioning, inhibitory avoidance (contextual fear), and extinction (Feder et al., 2009).

For example, Danoff-Burg \& Revenson (2005) found that patients with rheumatoid arthritis who found interpersonal benefits from the illness had less pain and lower psychological distress. Findings from a meta-analysis suggested that administration of DHEA mainly in women with adrenal insufficiency could improve mood and overall well-being (Panjari \& Davis, 2007). Suckling-related factors, which activate the brain oxytocin and prolactin systems, have also been found to be associated with a positive mood state (Heinrichs et al. 2001). However, a label of all these behavioural or neuronal factors as potential resilience is a relative (i.e., context-dependent), but not an absolute category. For example, in enhancing the rewarding value of social stimuli, empathy, trust and in reducing potential fear responses (Bakermans-Kranenburg \& van 
Ijzendoorn, 2008; Feder et al., 2009) oxytocin may be a resilience factor in the context of secure social attachments associated with passive coping strategies but a risk factor in others (e.g. competitive social circumstances associated with active coping strategies, which are more relevant for vasopressin effects as a resilience factor; Carter, Grippo, Pournajafi-Nazarloo, Ruscio, \& Porges, 2008; Donaldson, \& Young, 2008). Indeed, oxytocin might enhance the resilience (stress-alleviating) effects related to social attachment with safety or social support seeking behaviour relevant for societies with collective cultural values, and avoidance of noveltyrich environment found in societies with individualistic cultural values. In contrast, vasopressin might enhance the resilience (stress-alleviating) effects related to social engagement with competition and novelty seeking behaviour relevant for societies with individualistic cultural values and avoidance of low-risk environment found in societies with collective cultural values (see also discussion of moderation of individual- and group-level factors below).

\section{Measures of mental resilience}

Clinical psychologists generally seek to base their work on scientifically-proven assessment procedures. The methods used differ with regard to the population being served as well as the context and nature of the problem. In such a case, presentation and discussion of the mental resilience construct would be incomplete without discussion of procedures which have been used for mental resilience measurement.

As was once the case in immunology, some authors have argued that resilience cannot be directly measured, but only inferred from its two component constructs: risk and positive adaptation (Luthar \& Zelazo, 2003). Examples of this approach include the following: i) absence of psychopathology in high-risk samples (Alim et al., 2008; Parry et al., 2008); ii) in a chronic pain model, high scores on severity combined with low scores on interference and emotional burden (Karoly \& Ruehlman, 2006); iii) from longitudinal observation, an increase in mental distress 
symptoms during exposure to adversity followed by a subsequent return back to pre-exposure levels (Netuveli et al., 2008).

Other researchers have proposed that resilience, like somatic immunity, may be quantified while admitting that cross-cultural validity for these measures cannot be assumed (Connor \& Zhang, 2006; Diener et al., 2003). A number of scales have been developed (Ahern, Kiehl, Sole, \& Byers, 2006; Wagnild \& Young, 1993; Bartone, Ursano, Wright, \& Ingraham, 1989) or specific parameters extracted from other scales (Huppert \& Whittington, 2003) to measure resilience or its main components: for example, hardiness (Kobasa, 1979; Hull, Van Treuren, \& Virnelli, 1987), perceived stress (Cohen, Kamarck, \& Mermelstein, 1983), optimism and life attitude (Bowen, Morasca, \& Meischke, 2003). However, application of these measures has generally been restricted to specific populations (Carlson, 2001; Mosack, 2002), and generalisability cannot be assumed since the scales incorporate different constructs according to individual authors' concepts of resilience and underlying mechanisms.

Some scales have been more widely applied in community studies (e.g. an ego-resiliency scale by Block \& Kremen, 1996), while other scales have been recommended as more suitable for clinical research (Connor \& Davidson, 2003). For example, in a healthy sample, recent findings supported the convergent and discriminative validity of the Resilience Scale for Adults (RSA), it being argued that individuals scoring high on this scale are psychologically healthier, better adjusted, and thus more resilient (Friborg, Barlaug, Martinussen, Rosenvinge, \& Hjemdal, 2005). Another, the Resilience Scale (RS) was proposed as particularly suitable for the study of resilience in community samples on the basis of its psychometric properties and applicability in a variety of age groups (Ahern et al., 2006). This scale, similar to the RSA, was developed to measure primarily empirically derived factors associated with personality traits or coping resources that may prospectively determine resilience, but do not measure resilience itself. In contrast the Connor-Davidson Resilience Scale (CD-RISC) was developed as a brief self-rated assessment to 
help quantify resilience mainly in clinical settings to evaluate treatment response (Connor \& Davidson, 2003). An abbreviated form of this self-report scale consists of two items from the original 25 (Vaishnavi et al., 2007): namely "Able to adapt to change" and "Tend to bounce back after illness or hardship". These items were selected by the originators of the scale as etymologically capturing the essence of resilience related to protection and harm-reduction. Another example of this approach is the self-reported Posttraumatic Growth Inventory (PTGI; Tedeschi \& Calhoun, 1996), which assesses the essence of resilience related to mental health promotion in terms of a perceived growth from pre- to post-trauma - i.e. measuring a positive outcome following stress ('anti-stress training' or 'behavioural immunization' phenomenon).

Thus, one group of resilience scales (e.g. 2-item CD-RISC and PTGI) measures a subject's selfevaluation of his/her prior experience in successful overcoming stressful events and positive changes. These are likely to be reasonably robust cross-culturally, but require the presence of a stressor (or a research participant's recollection of their response to a previous one). In terms of a general immunity model these scales evaluate sensitivity to or efficiency of recovery from stress via anamnesis (prior life-related information) in the same way that a survey might measure a person's previous sensitivity to and efficiency of recovery from influenza or another common infection.

A second group of scales (like RSA and RS) measure subjective factors, which are empirically considered as determinants of resilience. However, the strong role played by authors' individual opinions and experience in determining underlying constructs for scales like the RS ('Personal competence' and 'Acceptance of self and life') and RSA ('Personal competence', 'Social competence', 'Structured style', 'Family cohesion', and 'Social resources') may limit their crosscultural applicability (Aroian, Schappler-Morris, Neary, Spitzer, \& Tran, 1997). In terms of an immunity model these scales measure potential factors related to level of resilience analogous to 
antibody titers or killer cells. Some authors have incorporated in their scale constructions from both approaches (e.g. the Ego-Resiliency Scale [ER-89] by Block and Kremen 1996).

A third or 'reactivity' approach involves measuring resistance to lower-level stressors encountered in daily life or through deliberate exposure to conditions with mental or physical effort contrast. Such approaches include the evaluation of balance of tolerance/sensitivity to regular stress through comparing work/non-work days or waking/sleeping states (Davydov, Shapiro, \& Goldstein, 2004; Davydov, Shapiro, et al., 2005; Davydov et al., 2009), or behavioural, subjective and physiological components of emotional reactivity to simple stimuli (e.g., pain), or complex information such as aversive tasks, films or texts in laboratory studies (Ottaviani, Shapiro, Davydov, Goldstein, Mills, 2009; Davydov et al., 2008; Lysenko \& Davydov, 2008). These tests of reactivity to minor stressors have been proposed to assess a level of adaptive or maladaptive coordination of behavioural and physiological responses in particular contexts as a trait representing a mood-protecting endophenotype and maintaining a balance of negative and positive experiences (Wichers et al., 2007a; Davydov et al., 2009). In terms of an immunity model, this group of measures is similar to the measurement of immunity/tolerance levels as in the Tuberculin Sensitivity Test to Mycobacterium tuberculosis invasion. However, measures from the second and the third groups of resilience measures have been found to be only weakly correlated (Mikolajczak, Roy, Luminet, \& de Timary, 2008).

The 'reactivity' approach to resilience measurement considers an adaptive reactivity as a common indicator of resilience (see Figure 2) which has been developed evolutionarily and ontogenetically at different (individual and group) levels and with different biopsychosocial mechanisms. Indeed, alternative transmissible behaviours (e.g. arousal versus relaxation) should be considered as components of a single adaptive or maladaptive strategy extended in time. Different human behaviours require different physical and mental efforts, which engage different physiological resources. The coupling of behavioural and physiological activities is coordinated by a complex 
central network (Jennings et al., 2009) and this coordination can be adaptive or maladaptive according to its correspondence to evolutionarily justified physiological reactivity to a definite challenge and in a definite condition (Davydov \& Ritchie, 2009; Verheyden et al., 2009). During evolution some behaviours have emerged due to their better reactivity to environmental challenges, others - for better recovery. Persons whose physiological responses best correspond with the underlying behaviour role requirement, as dictated by evolutionary conditions, have obtained an adaptive behaviour phenotype. For example, in environment-orienting conditions (during standing and apprehension of a threat) high sympathetic activity supports high physiological arousal for evolutionarily adaptive behaviour, i.e., processing of external afferentation (heightened vigilance and attention to detect threats). In non-environment-orienting conditions (during lying and after threat disappearing), suitable for rest and recovery, high sympathetic activity supports high arousal for evolutionary maladaptive behaviour, e.g., cognitive rumination (introspection).

Maladaptive control of behaviour-physiology coordination appears in people with negative mood or with poor health (Davydov \& Ritchie, 2009; Phillips, Der, \& Carroll, 2009). For example, abnormal physiological responses to behavioural activity (e.g., failure of SBP to increase appropriately in response to physical challenges) are associated with an increased risk of death, particularly in the young (Heradien et al., 2009). Findings from a recent community study suggest that if in a lying position a subject cannot inhibit cognitive and/or somatic activity following stress, this activity demands additional physiological resources, which results in an increase in SBP in the lying compared to standing posture and which is associated with an increase in negative feelings (Davydov \& Ritchie, 2009). Variables indexing reactivity and assessing behaviour-physiology coordination could help to assess individual resources of mental resilience to specific adversity (Davydov \& Ritchie, 2009; Phillips et al., 2009; see Figure 2). However, to consider BP activity as adaptive or maladaptive it should be additionally controlled for a coupled reactivity of myocardium metabolism (oxygen consumption) indexed, e.g., by the product of SBP 
and heart rate (Davydov, Shapiro, Cook, \& Goldstein, 2007b). Otherwise, high/low SBP reactivity depends on the environmental context as to whether it is adaptive or maladaptive. For example, children with low-cardiovascular reactivity were found to have less sensitivity to the external context and this phenotype was found to be advantageous if the context was aversive, but was associated with higher rates of illness under good (compared to poor) daycare conditions (Worthman, 2009). Twin studies have found that 5-HTTLPR homozygosity may influence individual differences in propensity for cardiovascular and behavioural responsivity to stressful events (McCaffery et al., 2003; Uher \& McGuffin, 2008).

The construct validity of resilience scales and measures has been mainly evaluated against an actual outcome representing resilience, such as the extent to which measured 'resilience' modifies the relationship between stressful life events and mental health status (Davydov \& Ritchie, 2009). In epidemiological studies, mental health status has been mainly measured by inventories including i) positive and negative mental health dimensions derived from instruments such as the General Health Questionnaire (GHQ), ii) positive mental health dimension like the 4-item Energy and Vitality Index (EVI), iii) general mental health dimensions like the 5-item Mental Health Inventory (MHI-5) of the Short Form-36 (SF-36) Health Survey instrument, Affect Balance Scale (ABS), Symptom Checklist (SCL), or the Patient Health Questionnaire (PHQ). For example, an index of positive well-being was derived from the 30- and 12-item General Health Questionnaires (Huppert \& Whittington, 2003; Hu, Stewart-Brown, Twigg, \& Weich, 2007), based upon positive responses to positive items (e.g. 'Have you recently felt on the whole you were doing things well?' as opposed to negative items such as 'Have you recently been feeling unhappy and depressed?'). This measure of positive well-being was compared with standard GHQ scoring for chronic psychological distress in a large sample of British adults. A substantial degree of independence between the two measures was found, and they were predicted by different factors. In the longitudinal component of this study, the absence of positive well-being at baseline was more strongly predictive of 7-year mortality than the presence of negative psychological 
symptoms (Huppert \& Whittington, 2003). However, such questionnaires have commonly been validated only against mental disorders, and their use as an indicator of mental well-being remains to be established (Keyes, 2002).

The List of Threatening Experiences (LTE-Q) (Brugha, Bebbington, Tennant, \& Hurry, 1985; Brugha \& Cragg, 1990; Stewart et al., 2002) has been frequently used to quantify the number of negative or stressful life events (such as bereavement). If adequately measured, patterns of health status and number of adversities should distinguish: i) mentally healthy people experiencing few negative life events (externally protected), ii) people with poorer mental health and many negative life events (vulnerable and non-resilient), iii) people with good mental health despite negative life events (resilient). One study found that a resilience scale, which measures possible protective factors, but not resilience as an outcome, poorly distinguished the well adjusted (externally protected) and resilient groups (Oshio, Kaneko, Nagamine, \& Nakaya, 2003) although this may be expected, if resilience, like somatic immunity, is a construct which is principally evident in the presence of adversity. Other scales, which measure resilience as a perceived outcome, have been criticised for their weak correlation with actual resilience outcomes (Frazier et al., 2009).

Limitations in the predictive validity of resilience scales may reflect distinctions between subjective and objective measures of factors related to resilience (Luthar et al., 2000). In most studies of resilience (e.g. Gillespie, Chaboyer, Wallis, \& Grimbeek, 2007) 'perceived' or 'reported' measures such as hope, self-efficacy, coping, control and competence are better predictors or correlates of individual resilience than 'received' or 'objective' variables such as education, income or duration employment. However, in these studies self-reported resilience may be an indicator of positive reinterpretation coping, but not actual resilience outcome after an adversity (Frazier et al., 2009). 
However, the distinction between subjective and objective measures of adversity is helpful in resilience evaluation. If a specific event is 'objectively' labelled as harmful in clinical inventories (e.g. bereavement or unemployment), but a subset of people subjectively perceive it as neutral, data from this group may be helpful in detecting protective processes, although it should be borne in mind that a characteristic conferring resilience in one respect may be a non-neutral (risk) factor for other outcomes. For example, persons perceiving negative events as neutral may be less affected due to high alexithymia, while, at the same time, higher alexithymia may worsen conditions related to other domains of human health (Stone \& Nielson, 2001; Bokeriia et al., 2008; Prkachin, Casey, \& Prkachin, 2009).

\section{Some challenges for future resilience research}

Challenge 1: Moderation of individual- and group-level factors: It should be noted that not all environmental challenges may be buffered by natural (i.e. individual) resilience, and individual resilience should be analyzed within the context of artificial (i.e. group-level) protective factors or barriers (Sameroff \& Rosenblum, 2006), just as the somatic immune system is explored in the context of trade-off with somatic hygiene (Yazdanbakhsh et al., 2002). As is found with vaccinations, group resilience factors can affect (transform or suppress) the development of individual resilience (Hunter, 2001).

There are different examples of such group and individual resilience factor interactions from national to community levels, from political to social-orienting strategies (Steptoe \& Wardle, 2001; Arrindell, Steptoe, \& Wardle, 2003). For example, a political decision to liberalize social relationships was suggested to favour the development of resilience at an individual level (antistress training with increase of individual tolerance to stress) at the expense of group resilience factors (anti-stress fortification with increase of individual sensitivity to stress), and was suggested as a factor underlying an increased frequency of mental disorders and behaviour problems over 90 years in Russia and other former socialistic states of Eastern Europe (Davydov 
\& Nepomnjashchiy, 2009; Nepomnyashchiy \& Davydov, 2007; Steptoe \& Wardle, 2001). Within the society of the former Soviet Union, the government-funded development of moral education emphasising absolute (unlimited) trust, may have generated a sense of guilt in the context of interpersonal conflicts (Davydov \& Nepomnjashchiy, 2009; Nepomnyashchiy \& Davydov, 2007) as a more constructive and adaptive social emotion in contrast to shame (Orth, Berking, \& Burkhardt, 2006). This in turn may have led to improvements in psychological and subjective well-being among Soviet people. However, prospective research suggested that this factor of group level resilience might have inhibited development of individual resilience in response to the challenges of capitalistic relationships based on contract- and guarantee-related 'trust', individualization, and a sense of shame and social comparison.

Thus, political and social institutions building group resilience factors may help people to be protective against stressors and to have higher well-being level in some conditions, but can lead to individual maladaptive responses and lower well-being in other circumstances. Thus, benefiting from group (e.g. socialist societies or societies with collective cultural values) and individual (e.g. capitalistic societies or societies with individualistic cultural values) resilience demands building a balance between society-dependency (to the detriment of individual resilience) and society-independence (to the detriment of group resilience) mechanisms. This challenge is closely related to individual difference in level of arousability to maintain a balance of positive and negative experience (see above). For example, high sensation-seeking persons (i.e., with stress- or risk-tolerant phenotypes) may consider a society with higher group resilience as detrimental for them, although this may be more comfortable for persons who are more riskaversive (i.e., with stress- or risk-sensitive phenotypes). Results of a recent study have been consistent with these inferences and have suggested that the social and physical environments associated with societies with collective cultural values (i.e., maintenance of social harmony over assertion of individuality) have a resilience effect against affective disorders in nations with high prevalence of individuals carrying the short (s) allele of the 5-HTTLPR (Chiao \& Blizinsky, 
2010). As mentioned above these individuals have a phenotype associated with high avoidance of a novelty-rich environment and high baseline arousability. In contrast long (l) allele carriers or individuals with low baseline arousability phenotype exhibit positive mood when taking risks, which promotes greater resilience against affective disorders in societies with individualistic cultural norms of self-expression and autonomy.

Thus, for development of a high quality of life for most citizens each society may need to build its own balance between group and individual resilience mechanisms according to population ratio in persons with high and low arousability phenotypes (i.e., low/high risk-orienting behaviour) or changing this ratio by environmental (e.g., political, economical, cultural, or psychological) control of phenotypical development (e.g., recommendations for phenotypically adapted psychotherapy, education, training, migration, food and drug intervention programs, see also Tables 1 and 2).

\section{Challenge 2: Mediating relationships between different resilience factors: The complex} interrelationships between different resilience factors, possibly specific to particular health states, are challenging for research and may underlie inconsistent findings. For example, sympathetic hyperactivity, which is commonly found in anxiety disorders and in a subgroup of patients with major depression, is regulated by a variety of neurotransmitters and neuropeptides (Morgan, Krystal, \& Southwick, 2003), which are associated with genetic variations having either risk or resilience effects (Southwick et al., 2005). Similarly, religion/spirituality as a resilience factor may be associated with meaning in life, a broad form of social support, greater access to resources through regular attendance at church/services, but also at another level may determine diet, exercise, alcohol and tobacco use (Fredrickson, 2002).

Strengthening one resilience factor may well have positive effects on other factors. For example using a time-lag model for the prediction of depression, Holahan, Holahan, Moos and Moos (1995) found that high social support predicted less subsequent depression in patients with acute 
and chronic cardiac illness, and that this relationship was partly mediated by the use of an active coping style. Higher social support in this case preceded and facilitated the use of active coping mechanisms. Curtis and Cicchetti (2003), and Rutter (2006) have argued that a comprehensive research agenda is needed, spanning biological, cognitive and social factors, and employing qualitative and quantitative methodologies. This approach demands more comprehensive statistical evaluation of the variety of direct and indirect, simple and multiple mediation, moderation, mediated moderation, confounding and suppression effects with combinations of latent and measured variables in models involving multiple outcome measures, nonlinear effects, multilevel designs, and strategies to evaluate the effects of missing data (Preacher \& Hayes, 2004, 2008; Jin et al., 2009).

Challenge 3: Specificity of resilience mechanisms: Though the importance of individual and group (e.g., family, community, and social) levels as barriers against different adversities has been found in various studies, their specificity regarding specific health domains has yet to be clarified (Luthar et al., 2000). The presence of a resilience factor for one health domain (e.g. affective symptoms) does not by itself imply a role in others (e.g. somatic, cognitive or behavioural symptoms). Moreover, similar to the pathogen specificity of an immune barrier, resilience against one type of risk factor for a given outcome (e.g. bereavement and depression) may differ from resilience against another risk factor for the same outcome (Maj, 2008; Kendler, Myers, \& Zisook, 2008). Resilience mechanisms and factors may also be different in relation to a range of context severity: from resilience against regular everyday hassles (like work stress) found in the majority (resilience to a 'regular' mild adversity) to resilience against occasional extensive stress (such as bereavement) found in minorities (resilience to a strong adversity). The use of absent (or low severity) psychopathology in a high-risk sample as an indicator of resilience may be evaluating a wide variety of different cognitive, somatic, behavioural and affective domains of mental disorder and thus may decrease the effect size of any specific resilience effect (Alim et al., 2008; Parry et al., 2008). The use of greater precision in terminology may help. For 
example, factors associated with positive mental health outcomes may be more easily ascertained because the outcome in question can be more specifically defined and may even be a better predictor of wider health status. This is supported by research into an index of positive well-being derived from the 30- and 12-item General Health Questionnaires (Huppert \& Whittington, 2003; Hu, Stewart-Brown, Twigg, \& Weich, 2007). In addition more recent statistical studies have shown categorical (taxonic) outcomes (such as diagnosis) to be less valid than dimensional approaches (e.g. in distinguishing depressed vs. nondepressed individuals, Beach \& Amir, 2003, 2006; Ruscio \& Ruscio, 2002; Baldwin \& Shean, 2006; Okumura, Sakamoto, Tomoda, \& Kijima, 2009). The development of more robust continuous measures of negative symptoms and positive states are thus required, for the evaluation of outcome specificity in risk and resilience factor interactions.

Challenge 4: Time lag in resilience: A central challenge for resilience research is to develop a theoretical model which could differentiate factors and mechanisms promoting well-being in the short-, medium- and long-term. Different resilience factors and different indicators of the resilience process may need to be evaluated at different times in order to identify effects. Some mental health promoting factors (as with active immunization in a communicable disease model) need more time for development to show a resilience effect. For example, higher birth weight or absence of early abuse will protect against psychopathology in old ages (Thompson, Syddall, Rodin, Osmond, \& Barker, 2001; Collishaw et al., 2007; Ritchie et al., 2009), but a factor itself could be associated with previous changes in some social factors for impact in subsequent populations (e.g. improvement in maternal healthcare). Effects of other health promoting processes (as with passive immunization) may be seen over a shorter time period (for example, some environmental community-level programmes, Minkler, Vásquez, \& Shepard, 2006). These examples highlight a further issue which is the importance of a life-course approach: because early-developed promotion factors may be modified by or mediated through factors in later life, 
and because there may be interactions between adversities and protective factors at different stages of development (Rutter, 1985; 2006).

Challenge 5: Cost and organizational complications of resilience research: A principal challenge for complex resilience research is to develop mechanisms of financial, organizational and political cooperation across and between countries for the integration of multi-disciplinary scientific groups - from genes to cultures with developmental mediating process. Due to deficient understanding of mental resilience as a biopsychosocial construct demanding multidisciplinary attention, research studies and meetings to date have tended to conceptualize the aetiology of resilience through simple mono-causal (not interacting) effects of psychosocial exposures (e.g. social support) and other health factors (e.g. exercise, nutrition). Moreover, these programmes and conferences have not been able to successfully integrate information relating to the biological components of resilience. Biological markers of resilience could in fact usefully complement socio-demographic and psychosocial measures. A broader biopsychosocial approach focusing on health promoters and protectors across the life-course would help to define resilience more precisely with a view to identifying modifiable factors and formulating intervention strategies. Thus, future initiatives on mental resilience should formulate mental health guidelines based on a framework of interacting biological, psychosocial and environmental constituents of mental health regulation (e.g. gene-environment interactions, epigenetic or 'plasticity gene' mechanisms).

However, a multidisciplinary biopsychosocial approach to resilience research is likely to be both expensive and organizationally complex, requiring cooperation across countries and research centres, and novel methodological approaches. Centres maintaining national genetic, clinical, and population databases could provide baseline data, which may serve as the basis of future multidisciplinary and transnational dialogue. To be scientifically, clinically, socially, economically and politically justified, the initiative should harmonise studies assessing a variety of potential and actual biopsychosocial resilience factors and mechanisms protecting and 
promoting mental health in groups at high risk across nations (e.g. women, older adults, disabled persons, victims of conflict, the bereaved and the unemployed). To achieve this objective, unification of several groups of factors and indicators (such as perceived vs. actual level of resilience, and potential vs. actual mechanisms or processes) is required in terms of how these determine resilience levels across the life course.

All resilience indicators and associated assessment instruments should be evaluated to identify and exclude duplication in measurement of similar aspects of health and in terms of their feasibility for data collection and unambiguous interpretation. National databases with these indicators would benefit from compilation into one information infrastructure (sharing data and knowledge resources across participants) together with a set of further indicators of mental resilience recommended or implemented by other public health or scientific programmes to could be classified as (i) fully standardized for low-level comparative analysis, (ii) partly standardized and only suitable for high-level comparative meta-analysis, (iii) not standardized and suitable for national or local usage only. Such an initiative would stimulate the development of new resilience markers through collaboration between innovative fundamental research (e.g. immunology, neuroscience) and psycho-social research (psychiatry/psychology, social science, epidemiology, economics and politics).

Failure to develop adequate biopsychosocial methodologies in resilience research will limit opportunities for obtaining financial support for more ambitious international initiatives. Multidisciplinary and transcultural studies are likely to have the highest potential to clarify the complex processes underlying resilience and their impact on the preservation of mental health in adversity.

\section{Conclusion}

In this review we conclude that resilience approach in mental health research is currently hindered by the lack of a unified methodology and poor concept definition. We have 
consequently investigated the extent to which a multi-level model of somatic immunity can be applied to multi-level biopsychosocial models of mental resilience. We further propose a biological component as an evolutionarily-developed background of variations in hereditary responses to challenges (stressors). These biological predispositions are shaped to a range of personal adaptive and maladaptive reactivities (e.g., skills for coping behaviours) through individual development (the psychological component) interacting with different social factors (the sociological component). Similar to the concept of somatic immunity, the concept of mental resilience is crucial to our understanding of how risks may be modified and disorders prevented. Application of a general immunity model as a common framework to resilience research in mental health can help to clarify underlying mechanisms and challenges, which contribute to our understanding of health in general and mental health in particular. Such a common framework would help in the discussion of resilience in terms of (i) multi-level defence barriers from transfer of adaptive (health) to maladaptive (disorder) reactivity, (ii) a balance of biological, psychological and social interactive effects for developing an adaptive trade-off between tolerance and sensitivity to stress.

The resilience approach is in keeping with the World Health Organization's conceptualization of mental health as a positive state of psychological well-being going beyond the absence of disease (World Health Organization, 2005). Such a construct can be found in the combination of positive feelings of subjective well-being together with positive functioning in daily life which has been described as 'flourishing' (Keyes, 2002). The absence of mental disorder cannot therefore be taken to be synonymous with mental health, and positive well-being cannot be conceptualized, measured or explained simply as the inverse of poor mental health (Keyes, 2002; Diener \& Lucas, 2000). It should now include factors and mechanisms determining level of protection against adversities, and rates of health promotion and harm-reduction processes in aversive conditions arising from a balance maintained by negative and positive experience as described according to an arousal-related homeostatic hypothesis. This balance of remembered early positive experience 
and remembered successful coping with stressful episodes may contribute to well-being through more effective coping (Tugade, Fredrickson, \& Barrett, 2004). However, resilience mechanisms should not be restricted to the individual level but must also be considered to be the result of a variety of group-level (e.g., community and cultural) factors and their interactions.

The resilience construct helps reconceptualise health disturbance in terms of resilience deficiency (poor protection quality) and defect (health-promotion or harm-reduction malfunction) utilising alternative frameworks (e.g. immune deficiency and defective somatic health protection systems). This approach addresses concerns regarding the description of abnormal behaviours (e.g., anxious arousal, anxiety apprehension, heightened vigilance and attention to the threat) in terms of its causes and why it occurs in some people but not in others (Kiesler, 1999) and moves towards describing them as variants of normal behaviour, explaining their evolutionary and ontogenetic roots and why they may be adaptive in some contexts but not in others (Gilbert, 2001).

In an evolutionary context, the protection of biological systems cannot be developed against all possible challenges, therefore, the function of some specific protection systems must be extended through a restricted range of non-specific defence mechanisms (general anti-stress fortification) and mechanisms with reserve for specific (anti-stress) training. Thus, the resilience approach may help to simplify selection and evaluation of interventions (e.g., psychotherapies) compared to the traditional health risk-related approaches (Kiesler, 1999).

For the purposes of public health intervention, resilience research should not only identify those members (countries, social groups or individuals) of a surveyed 'at risk' sample who demonstrate resilience, but also identify the specific characteristics of resilient groups or individuals. Failure to investigate these factors will hamper our ability to understand mental health problems and hence promote good mental health (Patel \& Goodman, 2007). Protective factors have an additional powerful indirect role in mitigating the effect of risk factors and should be measured 
simultaneously, without simply assuming that the former are the converse of the latter. However, deficit and defects in measurement instruments may limit validation of resilience factors and mechanisms.

Because resilience relating to positive adult experiences may stem from childhood protection against adversities, a life-span trajectory approach is needed to understand the constellation of interacting biological, psychological, social factors that determine, develop or modify resilience (Bennett, 2008). Also, because of the crucial importance of gene-environment interactions with various epigenetic, 'plasticity genes' and 'meaning change' mechanisms relating to resilience, a wide range of research strategies spanning psychosocial and biological methods is needed.

Moreover, in mental health resilience, neutral or risk attributes of a factor should be considered not in absolute, but in relative terms, when considering effects on a phenotype functioning in a specific environmental context.

The current review argues that studies of mental resilience should involve research on 1) both internal (individual-related) and external (group-related) levels of 2) harm-reduction, protective and promotion mechanisms against maladaptive reactivity related to 3) internal (e.g., genetic) and external (stress events) factors with 4) various specificity related to a) general mental health or its particular domains, b) their positive and negative outcomes, c) particular or multiple adversities, and d) specific persons or groups of persons. This approach implies that only multidisciplinary studies have the potential to clarify the complex relationships among genotype, phenotype, and biopsychosocial mechanisms of resilience to adversities and associated psychopathology.

Acknowledgements: We thank two anonymous reviewers for invaluable comments on early drafts. This research was supported by a 'Poste Vert' fellowship from the Institut National de la Santé et de la Recherche Médicale (INSERM), France granted to Dmitry M. Davydov. 
Declaration of Interest: none declared. 


\section{References}

Adler, R.H. (2009). Engel's biopsychosocial model is still relevant today. Journal of Psychosomatic Research, 67, 607-611.

Ahern, N.R., Kiehl, E.M., Sole, M.L., \& Byers, J. (2006). A review of instruments measuring resilience. Issues in Comprehensive Pediatric Nursing, 29, 103-125.

Akbarian, S., \& Huangm, H.-S. (2009). Epigenetic regulation in human brain-focus on histone lysine methylation. Biological Psychiatry, 65, 198-203.

Alim, T.N., Feder, A., Graves, R.E., Wang, Y., Weaver, J., Westphal, M., et al. (2008). Trauma, resilience, and recovery in a high-risk African-American population. American Journal of Psychiatry, 165, 1566-1575.

Alpert, J.E., Mischoulon, D., Nierenberg, A.A., \& Fava, M. (2000). Nutrition and depression: Focus on folate. Nutrition, 16, $544-581$.

Aroian, K.J., Schappler-Morris, N., Neary, S., Spitzer, A., Tran, T.V. (1997). Psychometric evaluation of the Russian Language version of the Resilience Scale. Journal of Nursing Measurement, 5, 151-164.

Arrindell, W.A., Steptoe, A., \& Wardle, J. (2003). Higher levels of state depression in masculine than in feminine nations. Behaviour Research and Therapy, 41, 809-817.

Bakermans-Kranenburg, M.J., \& van Ijzendoorn, M.H. (2007). Research Review: Genetic vulnerability or differential susceptibility in child development: The case of attachment. Journal of Child Psychology and Psychiatry, and Allied Disciplines, 48, 1160-1173.

Bakermans-Kranenburg, M.J., \& van Ijzendoorn, M.H. (2008). Oxytocin receptor (OXTR) and serotonin transporter (5-HTT) genes associated with observed parenting. Social Cognitive and Affective Neuroscience, 3, 128-134.

Baldwin, G., \& Shean, G.D. (2006). A taxometric study of the Center for Epidemiological Studies Depression Scale. Genetic Social and General Psychology Monographs, 132, 101-128. 
Bartone, P.T., Ursano, R., Wright, K., \& Ingraham, L. (1989). The impact of military air disaster on the health of assistance workers. The Journal of Nervous and Mental Disease, 177, 317 328.

Beach, S.R.H., \& Amir, N. (2003). Is depression taxonic, dimensional, or both? Journal of Abnormal Psychology, 112, 228-236.

Beach, S.R.H., \& Amir, N. (2006). Self-reported depression is taxonic. Journal of Psychopathology and Behavioral Assessment, 28, 171-178.

Becoña, E. (2007). [Resilience and drug consumption: A review]. Adicciones, 19, 89-101.

Belsky, J., Jonassaint, C., Pluess, M., Stanton, M., Brummett, B., \& Williams, R. (in press). Vulnerability genes or plasticity genes? Molecular Psychiatry.

Bennett, A.J. (2008). Gene environment interplay: Nonhuman primate models in the study of resilience and vulnerability. Developmental Psychobiology, 50, 48-59.

Block, J., \& Kremen, A.M. (1996). IQ and ego-resiliency: Conceptual and empirical connections and separateness. Journal of Personality and Social Psychology, 70, 349-361.

Bokeriia, L.A., Golukhova, E.Z., Polunina, A.G., Davydov, D.M., Kruglova, M.V. (2008). Alexithymia, depression and heart rate in candidates for cardiac surgery. International Journal of Cardiology, 126, 448-449.

Bonanno, G.A. (2004). Loss, trauma, and human resilience: have we underestimated the human capacity to thrive after extremely aversive events? American Psychologist, 59, 20-28.

Bonanno, G.A., Wortman, C.B., Lehman, D.R., Tweed, R.G., Haring, M., Sonnega, J., et al. (2002). Resilience to loss and chronic grief: A prospective study from preloss to 18 -months postloss. Journal of Personality and Social Psychology, 83, 1150-1164.

Borrell-Carrió, F., Suchman, A.L., \& Epstein, R.M. (2004). The biopsychosocial model 25 years later: Principles, practice, and scientific inquiry. Annals of Family Medicine, 2, 576-582.

Bowen, D.J., Morasca, A.A., \& Meischke, H. (2003). Measures and correlates of resilience. Women Health, 38, 65-76. 
Brown, G.W., \& Harris, T.O. (2008). Depression and the serotonin transporter 5-HTTLPR polymorphism: A review and a hypothesis concerning gene-environment interaction. Journal of Affective Disorders, 111, 1-12.

Brugha, T. S. \& Cragg, D. (1990). The list of threatening experiences: The reliability and validity of a brief life events questionnaire. Acta Psychiatrica Scandinavica, 82, 77-81.

Brugha, T. S., Bebbington, P., Tennant, C. \& Hurry, J. (1985). The list of threatening experiences: A subset of 12 life event categories with considerable long-term contextual threat. Psychological Medicine, 15, 189-194.

Cameron, C.A., Ungar, M., \& Liebenberg, L. (2007). Cultural understandings of resilience: Roots for wings in the development of affective resources for resilience. Child and Adolescent Psychiatric Clinics of North America, 16, 285-301,vii-viii.

Carlson, D.J. (2001). Development and validation of a College Resilience Questionnaire. Dissertation Abstracts International, A (Humanities and Social Sciences), 62, 2025.

Carrey, N., \& Ungar, M. (2007). Resilience theory and the diagnostic and statistical manual: Incompatible bed fellows? Child and Adolescent Psychiatric Clinics of North America, 16, 497-513.

Carter, C.S., Grippo, A.J., Pournajafi-Nazarloo, H., Ruscio, M.G., \& Porges, S.W. (2008). Oxytocin, vasopressin and sociality. Progress in Brain Research, 170, 331-336.

Charles, S.T., \& Almeida, D.M. (2007). Genetic and environmental effects on daily life stressors: More evidence for greater variation in later life. Psychology and Aging, 22, 331-340.

Charney, D.S. (2004). Psychobiological mechanisms of resilience and vulnerability: Implications for successful adaptation to extreme stress. American Journal of Psychiatry, 161, 195-216.

Chiao, J.Y., Blizinsky, K.D. (2010). Culture-gene coevolution of individualism-collectivism and the serotonin transporter gene. Proceedings of the Royal Society of London. Series B, Biological sciences, 277, 529-537.

Cohen, S., Kamarck, T., \& Mermelstein, R. (1983). A global measure of perceived stress. Journal of Health and Social Behavior, 24, 386-396. 
Collishaw, S., Maughan, B., Goodman, R., \& Pickles, A. (2004). Time trends in adolescent mental health. Journal of Child Psychology and Psychiatry, and Allied Disciplines, 45, 13501362.

Collishaw, S., Pickles, A., Messer, J., Rutter, M., Shearer, C., \& Maughan, B. (2007). Resilience to adult psychopathology following childhood maltreatment: Evidence from a community sample. Child Abuse \& Neglect, 31, 211-229.

Connor, K.M., \& Davidson, J.R.T. (2003). Development of a new resilience scale: The ConnorDavidson Resilience Scale (CD-RISC). Depression and Anxiety, 18, 76-82.

Connor, K.M., \& Zhang, W. (2006). Recent advances in the understanding and treatment of anxiety disorders. Resilience: Determinants, measurement, and treatment responsiveness. CNS Spectrums, 11, 5-12.

Cooreman, M.P., Leroux-Roels, G., \& Paulij, W.P. (2001). Vaccine- and hepatitis B immune globulin-induced escape mutations of hepatitis B virus surface antigen. Journal of Biomedical Science, 8, 237-247.

Curtis, W.J., \& Cicchetti, D. (2003). Moving research on resilience into the 21st century: Theoretical and methodological considerations in examining the biological contributors to resilience. Development and Psychopathology, 15, 773-810.

Danoff-Burg, S., \& Revenson, T. A. (2005). Benefit-finding among patients with rheumatoid arthritis: Positive effects on interpersonal relationships. Journal of Behavioral Medicine, 28, $91-103$.

Davydov, D.M., \& Nepomnjashchiy, S.V. (2009). Effective social politics as a rational way of economical development in Russia. In: Research, expert, and informational support of national strategy for advanced national projects and programs. Vol. 1 (National strategic design and public administration) pp. 75-78, Moscow, Russia: ISISS RAS.

Davydov, D.M., Lavrova, T.N., \& Drozdov, A.Z. (2005). [Relationships between stress hormones, menstrual cycle and mood in females]. Social'naja i Klinicheskaja Psihiatrija (Social and Clinical Psychiatry), Suppl: XIV All-Russ Conf Psychiatr, S477 [Abstract]. 
Davydov, D.M., Ritchie, R. (2009). Postural blood pressure, mood regulation, and life stress [Abstract]. Psychophysiology, 46, s112.

Davydov, D.M., Shapiro, D., \& Goldstein, I.B. (2004). Moods in everyday situations: Effects of menstrual cycle, work, and personality. Journal of Psychosomatic Research, 56, 27-33.

Davydov, D.M., Shapiro, D., \& Goldstein, I.B. (2010). Relation of resting baroreflex activity to 24-hour blood pressure and mood in healthy subjects. Journal of Psychophysiology. In press.

Davydov, D.M., Shapiro, D., Cook, I.A., \& Goldstein, I.B. (2007b). Baroreflex mechanisms in major depression. Progress in Neuro-Psychopharmacology \& Biological Psychiatry, 31, 164177.

Davydov, D.M., Shapiro, D., Goldstein, I.B., \& Chicz-DeMet, A. (2005). Moods in everyday situations: Effects of menstrual cycle, work, and stress hormones. Journal of Psychosomatic Research, 58, 343-349.

Davydov, D.M., Shapiro, D., Goldstein, I.B., \& Chicz-DeMet, A. (2007a). Moods in everyday situations: Effects of combination of different arousal-related factors. Journal of Psychosomatic Research, 62, 321-329.

Davydov, D.M., Zech, E., \& Luminet, O. (2008). Autonomic hypo- or hyper-arousal response to sad stimuli. Psychophysiology, 45, S83 [Abstract].

Demyttenaere, K., Bruffaerts, R., Posada-Villa, J., Gasquet, I., Kovess, V., Lepine, J.P., et al. (2004). Prevalence, severity, and unmet need for treatment of mental disorders in the World Health Organization World Mental Health Surveys. JAMA, 291, 2581-2590.

Diener, E., \& Lucas, R.E. (2000). Subjective emotional well-being. In M. Lewis, \& J.M. Haviland-Jones (Eds.), Handbook of Emotions (2nd Edition) (pp. 325-337). New York: Guilford Press.

Diener, E., Oishi, S., \& Lucas, R.E. (2003). Personality, culture, and subjective well-being: Emotional and cognitive evaluations of life. Annual Review of Psychology, 54, 403-425.

Donaldson, Z.R., \& Young, L.J. (2008). Oxytocin, vasopressin, and the neurogenetics of sociality. Science, 322, 900-904. 
Earvolino-Ramirez, M. (2007). Resilience: A concept analysis. Nursing Forum, 42, 73-82.

Eisenberg, N., \& Spinrad, T.L. (2004). Emotion-related regulation: sharpening the definition. Child Development, 75, 334-339.

Ellis, B.J., \& Boyce, W.T. (2008). Biological sensitivity to context. Current Directions in Psychological Science, 17, 183-187.

Ellis, B.J., Jackson, J.J., \& Boyce, W.T. (2006). The stress response systems: Universality and adaptive individual differences. Developmental Review, 26, 175-212.

Feder, A., Nestler, E.J., \& Charney, D.S. (2009). Psychobiology and molecular genetics of resilience. Nature Reviews. Neuroscience, 10, 446-457.

Felten, B.S., \& Hall, J.M. (2001). Conceptualizing resilience in women older than 85: Overcoming adversity from illness or loss. Journal of Gerontological Nursing, 27, 46-53.

Frazier, P., Tennen, H., Gavian, M., Park, C., Tomich, P., \& Tashiro, T. (2009). Does SelfReported Posttraumatic Growth Reflect Genuine Positive Change? Psychological Science, 20, 912-919.

Fredrickson, B.L. (2004). The broaden-and-build theory of positive emotions. Philosophical Transactions of the Royal Society of London. Series B, Biological Sciences, 359, 1367-1378.

Fredrickson, B.L., \& Joiner, T. (2002). Positive emotions trigger upward spirals toward emotional well-being. Psychological Science, 13, 172-175.

Fredrickson, B.L., \& Levenson, R.W. (1998). Positive emotions speed recovery from the cardiovascular sequelae of negative emotions. Cognition \& Emotion, 12, 191-220.

Fredrickson, B.L., Tugade, M.M., Waugh, C.E., \& Larkin, G. (2003). What good are positive emotions in crises? A prospective study of resilience and emotions following the terrorist attacks on the United States on September 11th, 2001. Journal of Personality and Social Psychology, 84, 365-376.

Fredrickson, BL. (2002). How does religion benefit health and well-being?: Are positive emotions active ingredients? Psychological Inquiry, 13, 209-213. 
Freedman, R. (2008). Coping, resilience, and outcome. American Journal of Psychiatry, 165, $1505-1506$

Freeman, M.P., Hibbeln, J.R., Wisner, K.L., Davis, J.M., Mischoulon, D., Peet, M., et al. (2006). Omega-3 fatty acids: Evidence basis for treatment and future research in psychiatry. Journal of Clinical Psychiatry, 67, 1954-1967.

Friborg, O., Barlaug, D., Martinussen, M., Rosenvinge, J.H., \& Hjemdal, O. (2005). Resilience in relation to personality and intelligence. International Journal of Methods in Psychiatric Research, 14, 29-42.

Friend, A., DeFries, J.C., \& Olson, R.K. (2008). Parental Education Moderates Genetic Influences on Reading Disability. Psychological Science, 19, 1124-1130.

Ghaemi, S.N. (2007). Pluralism in psychiatry: Karl Jaspers on science. Philosophy, Psychiatry, \& Psychology, 14, 57-66.

Ghaemi, S.N. (2009). The rise and fall of the biopsychosocial model: Reconciling art and science in psychiatry. Baltimore, Maryland: Johns Hopkins University Press.

Gilbert, P. (2001). Evolutionary approaches to psychopathology: The role of natural defences. The Australian and New Zealand Journal of Psychiatry, 35, 17-27.

Gillespie, B.M., Chaboyer, W., \& Wallis, M. (2007). Development of a theoretically derived model of resilience through concept analysis. Contemporary Nurse, 25, 124-135.

Gillespie, B.M., Chaboyer, W., Wallis, M., \& Grimbeek, P. (2007). Resilience in the operating room: Developing and testing of a resilience model. Journal of Advanced Nursing, 59, 427438.

Goldstein, B.I., Kemp, D.E., Soczynska, J.K., \& McIntyre, R.S. (2009). Inflammation and the phenomenology, pathophysiology, comorbidity, and treatment of bipolar disorder: a systematic review of the literature. The Journal of Clinical Psychiatry, 70, 1078-1090.

Gotay, C.C., Isaacs, P., \& Pagano, I. (2004). Quality of life in patients who survive a dire prognosis compared to control cancer survivors. Psychooncology, 13, 882-892. 
Green, H., McGinnity, A., Meltzer, H., Ford, T., \& Goodman, R. (2005). Mental health of children and young people in Great Britain, 2004. Basingstoke: Palgrave MacMillan.

Haeffel, G.J., \& Grigorenko, E.L. (2007). Cognitive vulnerability to depression: Exploring risk and resilience. Child and Adolescent Psychiatric Clinics of North America, 16, 435-448.

Harper, L.V. (2005). Epignetic inheritance and the intergenerational transfer of experience. Psychological Bulletin, 131, 340-360.

Harris, W.S. (2007). n-3 Fatty acid fortification: Opportunities and obstacles. British Journal of Nutrition, 97, 593-595.

Hegney, D.G., Buikstra, E., Baker, P., Rogers-Clark, C., Pearce, S., Ross, H. et al. (2007). Individual resilience in rural people: A Queensland study, Australia. Rural Remote Health, 7, 620.

Heinrichs, M., Meinlschmidt, G., Neumann, I., Wagner, S., Kirschbaum, C., Ehlert, U., et al. (2001). Effects of suckling on hypothalamic-pituitary-adrenal axis responses to psychosocial stress in postpartum lactating women. The Journal of Clinical Endocrinology and Metabolism, 86, 4798-4804.

Heinrichs, S.C., \& Koob, G.F. (2004). Corticotropin-releasing factor in brain: A role in activation, arousal, and affect regulation. The Journal of Pharmacology and Experimental Therapeutics, 311, 427-440.

Heradien, M., Revera, M., van der Merwe, L., Goosen, A., Corfield, V.A., Brink, P.A. et al. (2009). Abnormal blood pressure response to exercise occurs more frequently in hypertrophic cardiomyopathy patients with the R92W troponin T mutation than in those with myosin mutations. Heart Rhythm, 6, S18-S24.

Hibbeln, J.R., Ferguson, T.A., \& Blasbalg, T.L. (2006). Omega-3 fatty acid deficiencies in neurodevelopment, aggression and autonomic dysregulation: Opportunities for intervention. International Review of Psychiatry, 18, 107-118.

Hofer, M.A. (2006). Evolutionary basis of adaptation in resilience and vulnerability: Response to Cicchetti and Blender. Annals of the New York Academy of Sciences, 1094, 259-262. 
Hoge, E.A., Austin, E.D., \& Pollack, M.H. (2007). Resilience: Research evidence and conceptual considerations for posttraumatic stress disorder. Depression and Anxiety, 24, 139-152.

Holahan, C.J., Holahan, C.K., Moos, R.H., \& Moos, P.L. (1995). Social support, coping and depressive symptoms in a late-middle-aged sample of patients reporting cardiac illness. Health Psychology, 14, 152-163.

Hu, Y., Stewart-Brown, S., Twigg, L., \& Weich, S. (2007). Can the 12-item General Health Questionnaire be used to measure positive mental health? Psychological Medicine, 37, 10051013.

Hull, J.G., Van Treuren, R.R., \& Virnelli, S. (1987). Hardiness and health: A critique and alternative approach. Journal of Personality and Social Psychology, 53, 518-530.

Hunter, A.J. (2001). A cross-cultural comparison of resilience in adolescents. Journal of Pediatric Nursing, 16, 172-179.

Huppert, F.A. (2005). Positive mental health in individuals and populations. In F. Huppert, N. Baylis, \& B. Keverne (Eds.), The Science of Well-being (pp. 307-340). Oxford, England: Oxford University Press.

Huppert, F.A., \& Whittington, J.E. (2003). Evidence for the independence of positive and negative well-being: Implications for quality of life assessment. British Journal of Health Psychology, 8, 107-122.

Hutchinson, D.S., Gagne, C., Bowers, A., Russinova, Z., Skrinar, G.S., \& Anthony, W.A. (2006). A framework for health promotion services for people with psychiatric disabilities. Psychiatric Rehabilitation Journal, 29, 241-250.

Ickovics, J.R., Milan, S., Boland, R., Schoenbaum, E., Schuman, P., \& Vlahov, D. (2006). Psychological resources protect health: 5-year survival and immune function among HIVinfected women from four US cities. AIDS, 20, 1851-1860.

Jablonka, E. (2007). The developmental construction of heredity. Developmental Psychobiology, $49,808-817$. 
Jacelon, C.S. (1997). The trait and process of resilience. Journal of Advanced Nursing, 25, 123129.

Jennings, J.R., van der Molen, M.W., \& Tanase, C. (2009). Preparing hearts and minds: Cardiac slowing and a cortical inhibitory network. Psychophysiology, 46, 1170-1178.

Jessor, R., Turbin, M., \& Costa, F. (2003). Adolescent problem behaviour in China and the United States: A cross-national study of psychosocial protective factors. Journal of Research on Adolescence, 13, 329-360.

Jin, J., Tang, Y.-Y., Ma, Y., Lv, S., Bai, Y., \& Zhang, H. (2009). A structural equation model of depression and the defense system factors: A survey among Chinese college students. Psychiatry Research, 165, 288-296.

Jones, T. (2006). Resilience in homeless adults: A review of literature. Journal of National Black Nurses' Association, 17, 36-44.

Joseph, S., \& Linley, P.A. (2006). Growth following adversity: Theoretical perspectives and implications for clinical practice. Clinical Psychology Review, 26, 1041-1053.

Karoly, P., \& Ruehlman, L.S. (2006). Psychological "resilience" and its correlates in chronic pain: Findings from a national community sample. Pain, 123, 90-97.

Kaufman, J., Cook, A., Arny, L., Jones, B., \& Pittinsky, T. (1994). Problems defining resiliency: Illustrations from the study of maltreated children. Development and Psychopathology, 6, 215-229.

Kaufman, J., Yang, B.Z., Douglas-Palumberi, H., Grasso, D., Lipschitz, D., Houshyar, S. et al. (2006). Brain-derived neurotrophic factor-5-HTTLPR gene interactions and environmental modifiers of depression in children. Biological Psychiatry, 59, 673-680.

Kaufman, J., Yang, B.Z., Douglas-Palumberi, H., Houshyar, S., Lipschitz, D., Krystal, J.H. et al. (2004). Social supports and serotonin transporter gene moderate depression in maltreated children. Proceedings of the National Academy of Sciences of the United States of America, $101,17316-17321$. 
Kaul, R., Plummer, F.A., Kimani, J., Dong, T., Kiama, P., \& Rostron, T. (2000). HIV-1-specific mucosal CD8+ lymphocyte responses in the cervix of HIV-1-resistant prostitutes in Nairobi. Journal of Immunology, 164, 1602-1611.

Kendler, K.S., Myers, J., Zisook, S. (2008). Does bereavement-related major depression differ from major depression associated with other stressful life events? American Journal of Psychiatry, 165, 1449-1455.

Keyes, C.L. (2002). The mental health continuum: From languishing to flourishing in life. Journal of Health and Social Behavior, 43, 207-222.

Kiesler, D.J. (1999). Beyond the Disease Model of Mental Disorders. New York: Praeger.

Kim-Cohen, J. (2007). Resilience and developmental psychopathology. Child and Adolescent Psychiatric Clinics of North America, 16, 271-283.

Kobasa, S.C. (1979). Stressful life events, personality, and health: An inquiry into hardiness. Journal of Personality and Social Psychology, 37, 1-11.

Lerner, R.M. (2006). Resilience as an attribute of the developmental system: Comments on the papers of Professors Masten \& Wachs. Annals of the New York Academy of Sciences, 1094, 40-51.

Lewitus, G.M., \& Schwartz, M. (in press). Behavioral immunization: Immunity to self-antigens contributes to psychological stress resilience. Molecular Psychiatry.

Lewitus, G.M., Wilf-Yarkoni, A., Ziv, Y., Shabat-Simon, M., Gersner, R., Zangen, A., et al. (2009). Vaccination as a novel approach for treating depressive behavior. Biological Psychiatry, 65, 283-288.

Lin, P.Y., \& Su, K.P. (2007). A meta-analytic review of double-blind, placebo-controlled trials of antidepressant efficacy of omega-3 fatty acids. Journal of Clinical Psychiatry, 68, 1056-1061.

Linley, P.A., \& Joseph, S. (2004). Positive Psychology in Practice. Hoboken, New Jersey: Wiley. Lock, M. (1994). Menopause in cultural context. Experimental Gerontology, 29, 307-317. 
Luthar, S.S., \& Zelazo, L.B. (2003). Research on resilience: An integrative review. In S.S. Luthar (Ed.), Resilience and vulnerability: Adaptation in the context of childhood adversities (pp. 510-550). Cambridge, England: Cambridge University Press.

Luthar, S.S., Cicchetti, D., \& Becker, B. (2000). The construct of resilience: A critical evaluation and guidelines for future work. Child Development, 71, 543-562.

Lysenko, N.E., \& Davydov, D.M. (2008). Interplay of autonomic arousal and negative affect. International Journal of Psychophysiology, 69, 298 [Abstract].

Maj, M. (2008). Depression, Bereavement, and "Understandable" Intense Sadness: Should the DSM-IV Approach Be Revised? American Journal of Psychiatry, 165, 1373-1375.

Masten, A.S. (2007). Resilience in developing systems: Progress and promise as the fourth wave rises. Development and Psychopathology, 19, 921-930.

Masten, A.S., \& Obradovic, J. (2006). Competence and resilience in development. Annals of the New York Academy of Sciences, 1094, 13-27.

McCaffery, J.M., Bleil, M., Pogue-Geile, M.F., Ferrell, R.E., Manuck, S.B. (2003). Allelic variation in the serotonin transporter gene-linked polymorphic region (5-HTTLPR) and cardiovascular reactivity in young adult male and female twins of European-American descent. Psychosomatic Medicine, 65, 721-728.

McCormick, B.P., Frey, G.C., Lee, C.-T., Gajic, T., Stamatovic-Gajic, B., \& Maksimovic, M. (2009). A pilot examination of social context and everyday physical activity among adults receiving Community Mental Health Services. Acta Psychiatrica Scandinavica, 119, 243247.

McKenzie, K., Bhui, K., Nanchahal, K., \& Blizard, B. (2008). Suicide rates in people of South Asian origin in England and Wales: 1993-2003. The British Journal of Psychiatry, 193, 406409.

McNamara, R.K., Able, J., Liu, Y., Jandacek, R., Rider, T., Tso, P., et al. (2009). Omega-3 fatty acid deficiency during perinatal development increases serotonin turnover in the prefrontal 
cortex and decreases midbrain tryptophan hydroxylase-2 expression in adult female rats: Dissociation from estrogenic effects. Journal of Psychiatric Research, 43, 656-663.

Meltzer, H., Gatward, R., Goodman, R., \& Ford, T. (2000). Mental health of children and adolescents in Great Britain. Basingstoke: Palgrave MacMillan.

Mikolajczak, M., Roy, E., Luminet, O., de Timary, P., (2008). Resilience and hypothalamicpituitary-adrenal axis reactivity under acute stress in young men. Stress, 11, 477-482.

Miller, A.H. (2009). Mechanisms of cytokine-induced behavioral changes:

Psychoneuroimmunology at the translational interface. Brain, Behavior, and Immunity, 23, $149-158$.

Minkler, M., Vásquez, V.B., \& Shepard, P. (2006). Promoting environmental health policy through community based participatory research: A case study from Harlem, New York. Journal of Urban Health, 83, 101-110.

Morgan, C.A. 3rd, Krystal, J.H, \& Southwick, S.M. (2003). Toward early pharmacological posttraumatic stress intervention. Biological Psychiatry, 53, 834-843.

Mosack, K.E. (2002). The development and validation of the R-PLA: A resiliency measure for people living with HIV/AIDS (immune deficiency). Dissertation Abstracts International: Section B: the Sciences and Engineering, 62, 3844.

Müller-Thomsen, T., Arlt, S., Ganzer, S., Mann, U., Mass, R., Naber, D., et al. (2002). Depression in Alzheimer's disease might be associated with apolipoprotein E $\varepsilon 4$ allele frequency in women but not in men. Dementia and Geriatric Cognitive Disorders, 14, 59-63. Munafò, M.R., Brown, S.M., \& Hariri, A.R. (2008). Serotonin transporter (5-HTTLPR) genotype and amygdala activation: a meta-analysis. Biological Psychiatry, 63, 852-857.

Munafò, M.R., Durrant, C., Lewis, G., \& Flint, J. (2009). Gene X environment interactions at the serotonin transporter locus. Biological Psychiatry, 65, 211-219.

Nagata, C., Takatsuka, N., Inaba, S., Kawakami, N., \& Shimizu, H. (1998). Association of diet and other lifestyle with onset of menopause in Japanese women. Maturitas, 29, 105-113. 
Nepomnyashchiy, S.V, \& Davydov, D.M. (2007). Social-psychological aspects of terrorism origin and the role of the governmental social politics in counteraction to its development. In: The World Anticriminal and Antiterrorist Forum (WAAF): "The World community against the Globalization of Criminality and Terrorism” pp. 206-208 in English (pp. 50-53 in Russian). Moscow, Russia: Prospekt.

Nestler, E.J. (2009). Epigenetic mechanisms in psychiatry. Biological Psychiatry, 65, 189-190. Netuveli, G., Wiggins, R.D., Montgomery, S.M., Hildon, Z., \& Blane, D. (2008). Mental health and resilience at older ages: Bouncing back after adversity in the British Household Panel Survey. Journal of Epidemiology and Community Health, 62, 987-991.

Norcross, J.C., \& Goldfried, M.R. (2005). The future of psychotherapy integration: A roundtable. Journal of Psychotherapy Integration, 15, 392-471.

Norris, F.H., \& Murrell, S.A. (1988). Prior experience as a moderator of disaster impact on anxiety symptoms in older adults. American Journal of Community Psychology, 16, 665-683.

Norris, F.H., Stevens, S.P., Pfefferbaum, B., Wyche, K.F., \& Pfefferbaum, R.L. (2008). Community resilience as a metaphor, theory, set of capacities, and strategy for disaster readiness. American Journal of Community Psychology, 41, 127-50.

Okumura, Y., Sakamoto, S., Tomoda, A., \& Kijima, N. (2009). Latent structure of self-reported depression in undergraduates: Using taxometric procedures and information-theoretic latent variable modelling. Personality and Individual Differences, 46, 166-171.

Ong, A.D., Bergeman, C.S., Bisconti, T.L., \& Wallace, K.A. (2006). Psychological resilience, positive emotions, and successful adaptation to stress in later life. Journal of Personality and Social Psychology, 91, 730-749.

Orth, U., Berking, M., \& Burkhardt, S. (2006). Self-conscious emotions and depression: Rumination explains why shame but not guilt is maladaptive. Personality and social psychology bulletin, 32, 1608-1619.

Oshio, A., Kaneko, H., Nagamine, S., \& Nakaya, M. (2003). Construct validity of the Adolescent Resilience Scale. Psychological Reports, 93, 1217-1222. 
Ottaviani, C., Shapiro, D., Davydov, D.M, Goldstein, I.B., Mills P.J. (2009). The autonomic phenotype of rumination. International Journal of Psychophysiology, 72, 267-275.

Panjari, M. \& Davis, S.R. (2007). DHEA therapy for women: effect on sexual function and wellbeing. Human Reproduction Update, 13, 239-248.

Paracchini, S., Steer, C.D., Buckingham, L.-L., Morris, A.P., Ring, S., Scerri, T., et al. (2008). Association of the KIAA0319 dyslexia susceptibility gene with reading skills in the general population. American Journal of Psychiatry, 165, 1576-1584.

Parry, B.L., Meliska, C.J., Sorenson, D.L., Lopez, A.M., Martinez, L.F., Nowakowski, S., et al. (2008). Plasma melatonin circadian rhythm disturbances during pregnancy and postpartum in depressed women and women with personal or family histories of depression. American Journal of Psychiatry, 165, 1551-1558.

Patel, V., \& Goodman, A. (2007). Researching protective and promotive factors in mental health. International Journal of Epidemiology, 36, 703-707.

Pezawas L, Meyer-Lindenberg A, Drabant EM, Verchinski BA, Munoz KE, Kolachana BS et al. (2005). 5-HTTLPR polymorphism impacts human cingulate-amygdala interactions: a genetic susceptibility mechanism for depression. Nature Neuroscience, 8, 828-834.

Phillips, A.C., Der, G., \& Carroll, D. (2009). Self-reported health and cardiovascular reactions to psychological stress in a large community sample: Cross-sectional and prospective associations. Psychophysiology, 46, 1020-1027.

Preacher, K.J., \& Hayes, A.F. (2004). SPSS and SAS procedures for estimating indirect effects in simple mediation models. Behavior Research Methods, Instruments, and Computers, 36, 717 731.

Preacher, K.J., \& Hayes, A.F. (2008). Asymptotic and resampling strategies for assessing and comparing indirect effects in multiple mediator models. Behavior Research Methods, 40, 879891.

Prkachin, G.C., Casey, C., \& Prkachin, K.M. (2009). Alexithymia and perception of facial expressions of emotion. Personality and Individual Differences, 46, 412-417. 
Quinton, D., Rutter, M., \& Liddle, C. (1984). Institutional rearing, parenting difficulties and marital support. Psychological Medicine, 14, 107-124.

Regehr, C., Hemsworth, D., \& Hill, J. (2001). Individual predictors of posttraumatic distress: A structural equation model. Canadian Journal of Psychiatry, 46, 156-161.

Richardson, G.E. (2002). The metatheory of resilience and resiliency. Journal of Clinical Psychiatry, 58, 307-321.

Richardson, G.E., \& Waite, P.J. (2002). Mental health promotion through resilience and resiliency education. International Journal of Emergency Mental Health, 4, 65-75.

Ritchie, K., Jaussent, I., Stewart, R., Dupuy, A.M., Courtet, P., Ancelin, M.L. et al. (2009). Association of adverse childhood environment with late-life depression. The Journal of Clinical Psychiatry, 70, 1281-1288.

Rossi, A. (1962). Some pre-world War II antecedents of community mental health theory and practice. Mental Hygiene, 46, 78-98.

Rothermund, K., \& Brandtstädter, J. (2003). Depression in later life: Cross-sequential patterns and possible determinants. Psychology and Aging, 18, 80-90.

Rowland-Jones, S.L., Dong, T., Fowke, K.R., Kimani, J., Krausa, P., Newell, H., et al. (1998). Cytotoxic T cell responses to multiple conserved HIV epitopes in HIV-resistant prostitutes in Nairobi. The Journal of Clinical Investigation, 102, 1758-1765.

Ruscio, A.M., \& Ruscio, J. (2002). The latent structure of analogue depression: Should the Beck Depression Inventory be used to classify groups? Psychological Assessment, 14, 135-145.

Russo-Neustadt, A., Ha, T., Ramirez, R., \& Kesslak, J.P. (2001). Physical activity-antidepressant treatment combination: Impact on brain-derived neurotrophic factor and behavior in an animal model. Behavioural Brain Research, 120, 87-95.

Rutter, M. (1985). Resilience in the face of adversity. Protective factors and resistance to psychiatric disorder. The British Journal of Psychiatry, 147, 598-611.

Rutter, M. (2006). Implications of resilience concepts for scientific understanding. Annals of the New York Academy of Sciences, 1094, 1-12. 
Rutter, M., \& Quinton, D. (1984). Long-term follow-up of women institutionalized in childhood: Factors promoting good functioning in adult life. The British Journal of Developmental Psychology, 2, 191-204.

Rutter, M., \& Smith, D.J. (Eds.). (1995). Psychosocial disorders in young people. Chichester: Wiley.

Sameroff, A.J., \& Rosenblum, K.L. (2006). Psychosocial constraints on the development of resilience. Annals of the New York Academy of Sciences, 1094, 116-124.

Schaal, S., Elbert, T., \& Neuner, F. (2009). Narrative Exposure Therapy versus group Interpersonal Psychotherapy - a controlled clinical trial with orphaned survivors of the Rwandan genocide. Psychotherapy and Psychosomatics, (in press).

Schmidt, L.A., Fox, N.A., Perez-Edgar, K., \& Hamer, D.H. (2009). Linking gene, brain, and behavior: DRD4, frontal asymmetry, and temperament. Psychological Science, 20, 831-837.

Schneiderman, N., Ironson, G., \& Siegel, S.D. (2005). Stress and health: Psychological, behavioral, and biological determinants. Annual Review of Clinical Psychology, 1, 607-628.

Schore, A.N. (2001). Minds in the making: Attachment, the self-organizing brain, and developmentally-oriented psychoanalytic psychotherapy. British Journal of Psychotherapy 17, 299-328.

Seligman, M.E., \& Maier, S.F. (1967). Failure to escape traumatic shock. Journal of Experimental Psychology, 74, 1-9.

Shapiro, D., Jamner, L.D., Goldstein, I.B., \& Delfino, R.J. (2001). Striking a chord: Moods, blood pressure, and heart rate in everyday life. Psychophysiology, 38, 197-204.

Skinner, E.A., \& Zimmer-Gembeck, M.J. (2007). The development of coping. Annual Review of Psychology, 58, 119-144.

Slattery, D.A., \& Neumann, I.D. (2008). No stress please! Mechanisms of stress hyporesponsiveness of the maternal brain. The Journal of Physiology, 586, 377-385. 
Southwick, S.M., Vythilingam, M., \& Charney, D.S. (2005). The Psychobiology of depression and resilience to stress: Implications for prevention and treatment. Annual Review of Clinical Psychology, 1, 255-291.

Stanton, A.L., Revenson, T.A., \& Tennen, H. (2007). Health psychology: Psychological adjustment to chronic disease. Annual Review of Psychology, 58, 565-592.

Stawski, R.S., Sliwinski, M.J., Almeida, D.M., \& Smyth, J.M. (2008). Reported exposure and emotional reactivity to daily stressors: The roles of adult age and global perceived stress. Psychology and Aging, 23, 52-61.

Steiner, M., Dunn, E., \& Born, L. (2003). Hormones and mood: From menarche to menopause and beyond. Journal of Affective Disorders, 74, 67-83.

Steinhardt, M., \& Dolbier, C. (2008). Evaluation of a resilience intervention to enhance coping strategies and protective factors and decrease symptomatology. Journal of American College Health, 56, 445-453.

Steptoe, A., \& Wardle, J. (2001). Health behaviour, risk awareness and emotional well-being in students from Eastern Europe and Western Europe. Social Science \& Medicine, 53, 16211630.

Stewart, R., Prince, M., Harwood, R., Whitley, R., \& Mann, A. (2002). Quality of accommodation and risk of depression in later life: An analysis of prospective data from the Gospel Oak Project. International Journal of Geriatric Psychiatry, 17, 1091-1098.

Stone, L.A., \& Nielson, K.A. (2001). Intact physiological response to arousal with impaired emotional recognition in alexithymia. Psychotherapy and Psychosomatics, 70, 92-102.

Suchankova, P., Henningsson, S., Baghaei, F., Rosmond, R., Holm, G., \& Ekman, A. (2009). Genetic variability within the innate immune system influences personality traits in women. Genes, Brain and Behavior, 8, 212-217.

Sweatt, J.D. (2009). Experience-dependent epigenetic modifications in the Central Nervous System. Biological Psychiatry, 65, 191-197. 
Szyf, M., McGowan, P., \& Meaney, M.J. (2007). The social environment and the epigenome. Environmental and Molecular Mutagenesis, 49, 46-60.

Taylor, S.E., \& Stanton, A.L. (2007). Coping resources, coping processes, and mental health. Annual Review of Clinical Psychology, 3, 377-401.

Tedeschi, R., \& Calhoun, L. (1996). The Posttraumatic Growth Inventory: Measuring the positive legacy of trauma. Journal of Traumatic Stress, 9, 455-471.

Thompson, C., Syddall, H., Rodin, I., Osmond, C., \& Barker, D.J.P. (2001). Birth weight and the risk of depressive disorder in late life. The British Journal of Psychiatry, 179, 450-455.

Troisi, A. (2009). Cholesterol in coronary heart disease and psychiatric disorders: Same or opposite effects on morbidity risk? Neuroscience and Biobehavioral Reviews, 33, 125-132.

Tugade, M.M., \& Fredrickson, B.L. (2004). Resilient individuals use positive emotions to bounce back from negative emotional experiences. Journal of Personality and Social Psychology, 86, 320-333.

Tugade, M.M., Fredrickson, B.L., \& Barrett, L.F. (2004). Psychological resilience and positive emotional granularity: Examining the benefits of positive emotions on coping and health. Journal of Personality, 72, 1161-1190.

Tusaie, K., \& Dyer, J. (2004). Resilience: A historical review of the construct. Holistic Nursing Practice, 18, 3-8.

Uher, R., \& McGuffin, P. (2008). The moderation by the serotonin transporter gene of environmental adversity in the aetiology of mental illness: review and methodological analysis. Molecular Psychiatry, 13, 131-146.

Vaishnavi, S., Connor, K., \& Davidson, J.R.T. (2007). An abbreviated version of the ConnorDavidson Resilience Scale (CD-RISC), the CD-RISC2: Psychometric properties and applications in psychopharmacological trials. Psychiatry Research, 152, 293-297.

Vanderbilt-Adriance, E., \& Shaw, D.S. (2008). Conceptualizing and re-evaluating resilience across levels of risk, time, and domains of competence. Clinical Child and Family Psychology Review, 11, 30-58. 
Verhagen, M., van der Meij. A., van Deurzen, P.A.M., Janzing, J.G.E., Arias-Vásquez, A., Buitelaar, J.K. et al. (in press). Meta-analysis of the BDNF Val66Met polymorphism in major depressive disorder: Effects of gender and ethnicity. Molecular Psychiatry.

Verheyden, B., Liu, J., Beckers, F., \& Aubert, A.E. (2009). Adaptation of heart rate and blood pressure to short and long duration space missions. Respiratory Physiology \& Neurobiology, $169 S$, S13-S16.

Voracek, M., \& Loibl, L.M. (2008). Consistency of immigrant and country-of-birth suicide rates: A meta-analysis. Acta Psychiatrica Scandinavica, 118, 259-271.

Wachs, T.D. (2006). Contributions of temperament to buffering and sensitization processes in children's development. Annals of the New York Academy of Sciences, 1094, 28-39.

Wagnild, G.M., \& Young, H.M. (1993). Development and psychometric validation of the Resilience Scale. Journal of Nursing Measurement, 1, 165-178.

Waugh, C.E., Fredrickson, B.L., \& Taylor, S.F. (2008). Adapting to life's slings and arrows: Individual differences in resilience when recovering from an anticipated threat. Journal of Research in Personality, 42, 1031-1046.

Wichers, M., Kenis, G., Jacobs, N., Myin-Germeys, I., Schruers, K., Megelers, R. et al. (2008a). The psychology of psychiatric genetics: Evidence that positive emotions in females moderate genetic sensitivity to social stress associated with the BDNF Val Met polymorphism. Journal of Abnormal Psychology, 117, 699-704.

Wichers, M., Myin-Germeys, I., Jacobs, N., Peeters, F., Kenis, G., Derom, C. et al. (2007a). Genetic risk of depression and stress-induced negative affect in daily life. The British Journal of Psychiatry, 191, 218-223.

Wichers, M.C., Gunter, K. Jacobs, N., Mengelers, R., Derom, C., Vlietinck, R. et al. (2008b). The BDNF Val(66)Met x 5-HTTLPR x child adversity interaction and depressive symptoms: An attempt at replication. American Journal of Medical Genetics, 147B, 120-123.

Wichers, M.C., Myin-Germeys, I., Jacobs, N., Peeters, F., Kenis, G., Derom, C. et al. (2007b). Evidence that moment-to-moment variation in positive emotions buffer genetic risk for 
depression: A momentary assessment twin study. Acta Psychiatrica Scandinavica, 115, 451457.

Wichers, M.C., Schrijvers, D., Geschwind, N., Jacobs, N., Myin-Germeys, I., Thiery, E. et al. (2009). Mechanisms of gene-environment interactions in depression: evidence that genes potentiate multiple sources of adversity. Psychological medicine, 39, 1077-1086.

Wiltermuth, S.S., \& Heath, C. (2009). Synchrony and cooperation. Psychological Science, 20, 15.

Windle, G., Markland, D.A., \& Woods, R.T. (2008). Examination of a theoretical model of psychological resilience in older age. Aging \& Mental Health, 12, 285-292.

World Health Organization. (2005). Promoting Mental Health: Concepts, Emerging Evidence, Practice. Geneva: World Health Organisation.

Worthman, C.M. (2009). Habits of the heart: life history and the developmental neuroendocrinology of emotion. American Journal of Human Biology, 21, 772-81.

Yazdanbakhsh, M., Kremsner, P.G., \& van Ree, R. (2002). Allergy, parasites, and the hygiene hypothesis. Science, 296, 490-494.

Yehuda, R., \& Flory, J.D. (2007). Differentiating biological correlates of risk, PTSD, and resilience following trauma exposure. Journal of Traumatic Stress, 20, 435-447.

Young, E.A., \& Altemus, M. (2004). Puberty, ovarian steroids, and stress. Annals of the New York Academy of Sciences, 1021, 124-133. 
Fig. 1. Supplementary to Table 1, a general schema of interaction (crosses), feed forward (thin arrows) and backward (block arrows) effects within and between suggested levels and factors (mechanisms) within a 'Mental Health Protection' framework.

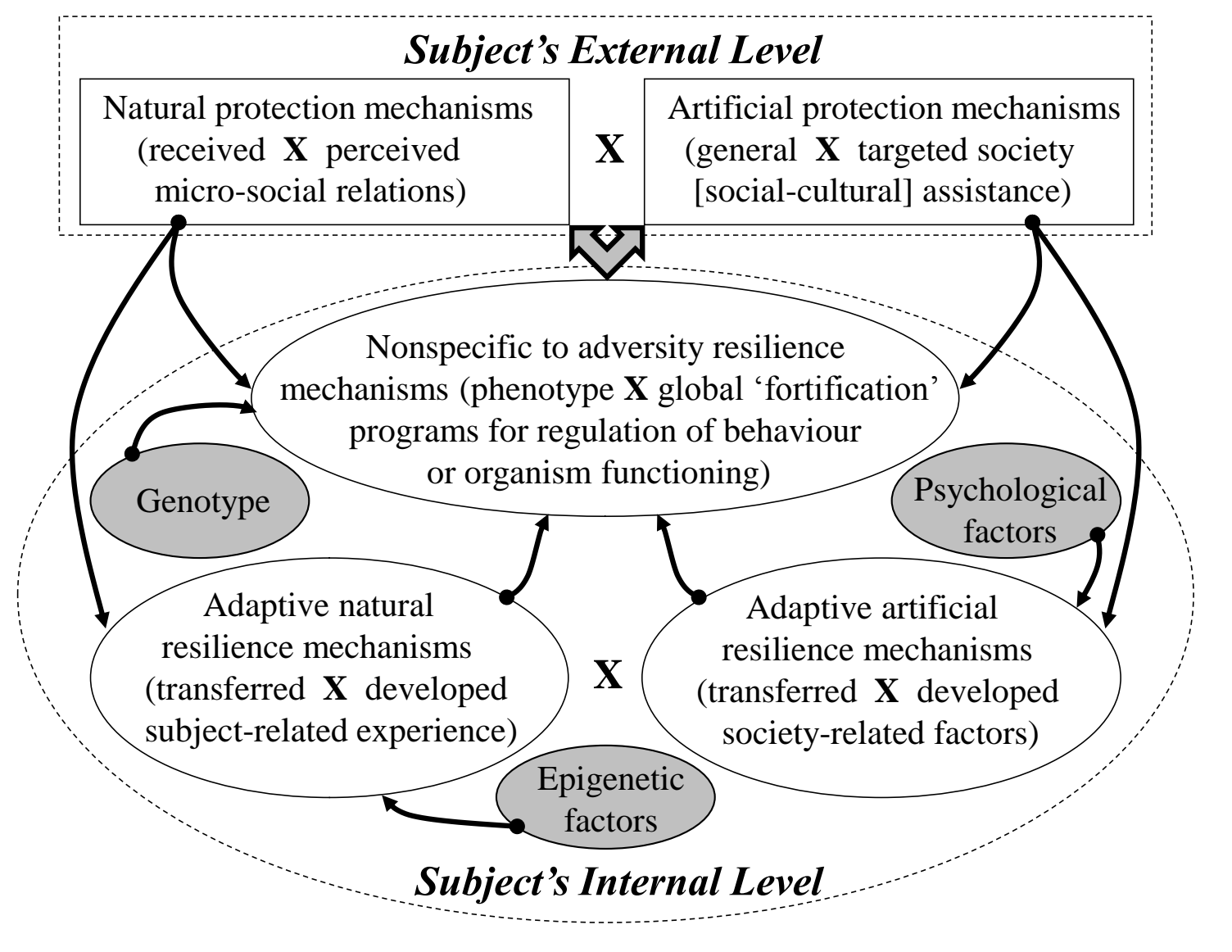


Fig. 2. Model of three Mental Resilience System mechanisms (health protection, promotion and harmreduction) in the face of aversive events (i.e., stressors with various power): before, during and after a health disturbance ${ }^{1}$.

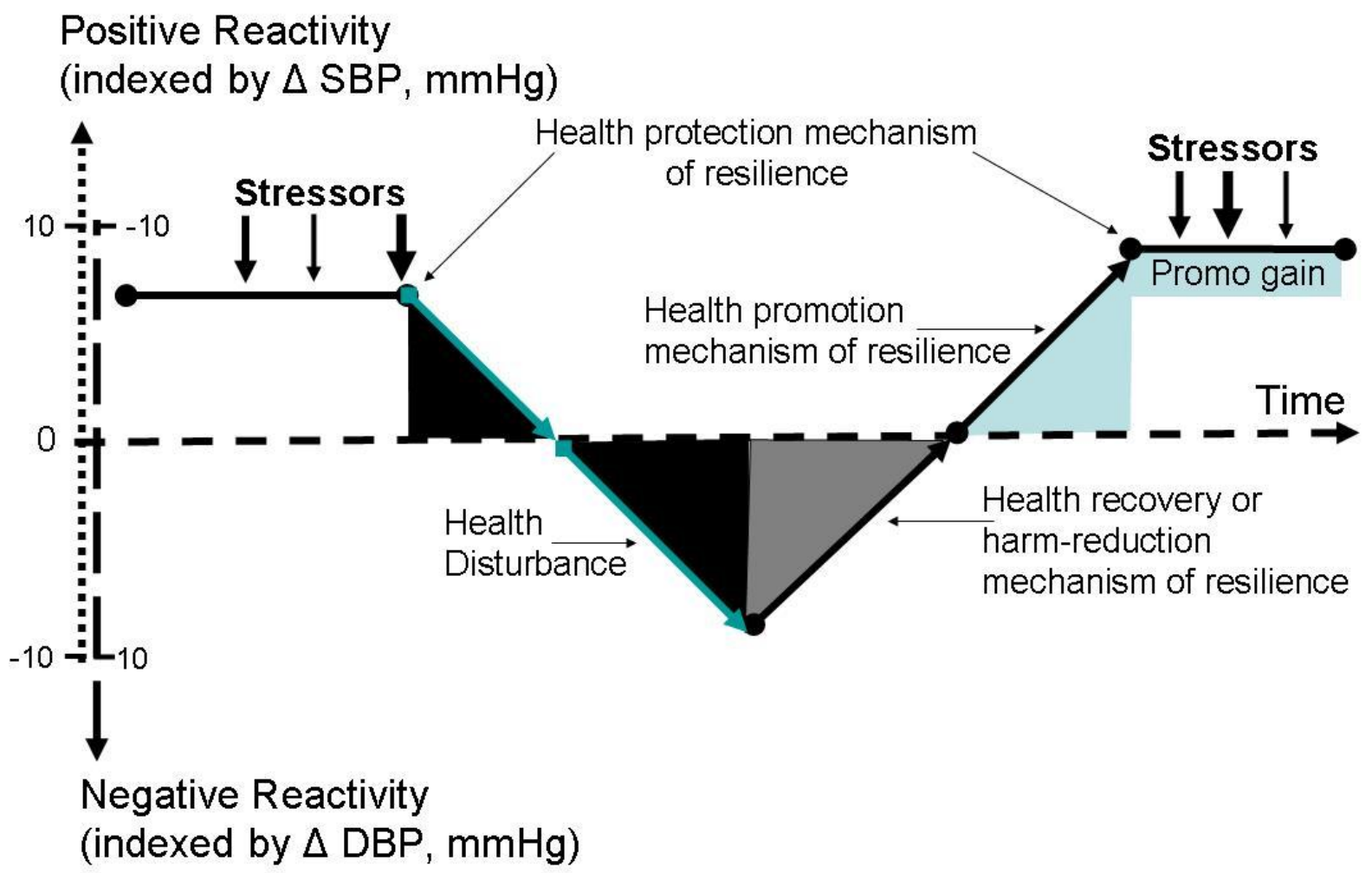

\footnotetext{
${ }^{1}$ In the present schema, capacity and changes in the Mental Resilience System are indexed by systolic blood pressure reactivity $(\triangle \mathrm{SBP})$ to challenges (arousal versus relaxed), which is positively associated with level of daily positive affect, but health disturbance is indexed by diastolic blood pressure reactivity $(\triangle \mathrm{DBP})$ to challenges (arousal versus relaxed), which is positively associated with level of daily negative affect (according to Davydov et al., 2009, Davydov \& Ritchie, 2009, and Phillips et al., 2009). Time scale is individual and may be related to minutes, hours, days, months, and years of specific person-environment interactions conferring neutral, risk or resilience effects. Promotion gain ('promo gain') may be related to (i) stressor-specific (i.e., wider protection indexed by gain of a number of specific stressors covered) or (ii) stressor-nonspecific (i.e., more powerful protection, e.g., indexed by SBP reactivity gain) increase in health protection aspect of resilience. The SBP and DBP reactivity scales are presented according to average population means and are not specified in relation to low or high reactivity phenotypes.
} 
Table 1. Cross-reference of somatic health protection and mental resilience systems, defending against disease by identifying and neutralizing adversities/pathogens on different layers/levels (a general schema of interrelations within and between suggested levels and factors (mechanisms) related to mental health cells is provided in Figure 1; examples of studies related to mental health cells are provided in Table 2)

\section{General Health Protection System}

Somatic Health Protection System

\begin{tabular}{lllll} 
I. External & Natural (subject- & $\begin{array}{l}\text { Artificial (society- } \\
\text { related factors) }\end{array}$ & $\begin{array}{l}\text { Natural (subject-related } \\
\text { factors and experience) }\end{array}$ & $\begin{array}{l}\text { Artificial (received from } \\
\text { society) }\end{array}$ \\
\hline
\end{tabular}

1. Nonspecific to adversity/pathogen barriers ${ }^{1}$

Quality of received surface physical and chemical barriers (e.g. skin)

Mental Health Protection System factors and experience) society)
Quality of received interpersonal relationships
Quality of general national, economical and cultural barriers

\section{Adaptive or specific Proximity to} to adversity/pathogen infectious agent barriers $^{2}$
Quality of received soap)

Quality of sanitary barriers (e.g. specific food control)
Quality of perceived social support
Quality of targeted assistance acquired from society

\section{General Immunity}

\begin{tabular}{lllll}
\hline & \multicolumn{2}{c}{ Immune System } & \multicolumn{1}{c}{ Mental Resilience System } \\
\cline { 2 - 5 } II. Internal & $\begin{array}{l}\text { Natural (subject- } \\
\text { Layers/Levels }\end{array}$ & $\begin{array}{l}\text { Artificial (society- } \\
\text { related factors) }\end{array}$ & $\begin{array}{l}\text { Natural (subject-related } \\
\text { factors and experience) }\end{array}$ & $\begin{array}{l}\text { Artificial (received from } \\
\text { society) }\end{array}$ \\
\hline
\end{tabular}

$\begin{array}{lll}\text { 1. Nonspecific to } & \begin{array}{l}\text { Inflammation } \\ \text { adversity/pathogen }\end{array} & \begin{array}{l}\text { National 'fortification' Phenotype advantages } \\ \text { programs (e.g. vitamin } \\ \text { enrichment) }\end{array}\end{array}$

'Fortification' programs for general regulation of behaviour or organism functioning in a community

\section{Adaptive or specific to adversity/pathogen barriers $^{2}$}

\begin{tabular}{|c|c|c|c|c|}
\hline $\begin{array}{l}\text { a) Passive barrier after } \\
\text { resilience/antibody } \\
\text { transfer }^{3}\end{array}$ & $\begin{array}{l}\text { Passive (maternal) } \\
\text { immunity after birth }\end{array}$ & Passive immunization & $\begin{array}{l}\text { Imprinting, implicit } \\
\text { learning }\end{array}$ & $\begin{array}{l}\text { Externally imposed } \\
\text { regulation of emotions } \\
\text { and behaviours in a } \\
\text { person }\end{array}$ \\
\hline $\begin{array}{l}\text { b) Active (acquired) } \\
\text { barrier after } \\
\text { adversity/antigen- } \\
\text { presentation }{ }^{4}\end{array}$ & $\begin{array}{l}\text { Infection-related } \\
\text { immunological } \\
\text { memory (principal in } \\
\text { childhood) }\end{array}$ & $\begin{array}{l}\text { Immunological } \\
\text { memory related to } \\
\text { active immunization } \\
\text { by vaccines }\end{array}$ & $\begin{array}{l}\text { Epigenetic and meaning } \\
\text { change mechanisms } \\
\text { related to real life } \\
\text { adversities (principal in } \\
\text { childhood) }\end{array}$ & $\begin{array}{l}\text { Cognitive reappraisals } \\
\text { related to cognitive } \\
\text { therapy }\end{array}$ \\
\hline
\end{tabular}

\footnotetext{
${ }^{1}$ the defence barrier, which leads to immediate maximal response to any adversity/pathogen

2 the defence barrier, which helps to adapt to recognised (specific) adversity/pathogens more efficiently

${ }^{3}$ the fast, but short-lasting defence barrier with resilience/antibody elements which were externally developed and transferred to a person for protection against a specific adversity/pathogen

${ }^{4}$ the late, but long-lasting defence barrier with resilience/antibody elements which were internally developed with a lag time between exposure and maximal response for protection against a specific adversity/pathogen after its recognition (identification) by the defence system
} 
Table 2. Supplementary to Table 1, specific examples of resilience within a 'Mental Health Protection' framework.

\begin{tabular}{|c|c|c|}
\hline \multirow[b]{2}{*}{ I. External Layers/Levels } & \multicolumn{2}{|c|}{ Mental Health Protection System } \\
\hline & $\begin{array}{l}\text { Natural (subject-related factors and } \\
\text { experience) }\end{array}$ & Artificial (received from society) \\
\hline $\begin{array}{l}\text { 1. Nonspecific to adversity } \\
\text { barriers }{ }^{1}\end{array}$ & $\begin{array}{l}\text { Potential interpersonal relations } \\
\text { providing a balance of 'positive } \\
\text { experience' and 'behavioural } \\
\text { immunization' in childhood (Ellis \& } \\
\text { Boyce, 2008) }\end{array}$ & $\begin{array}{l}\text { National barriers against political } \\
\text { violence (e.g., the Israel-Lebanon } \\
\text { border, Norris et al., 2008) }\end{array}$ \\
\hline $\begin{array}{l}\text { 2. Adaptive or specific to } \\
\text { adversity barriers }{ }^{2}\end{array}$ & $\begin{array}{l}\text { Perceived availability and quality of } \\
\text { potential social support against } \\
\text { posttraumatic distress (Regehr et al., } \\
\text { 2001) }\end{array}$ & $\begin{array}{l}\text { Targeted assistance acquired from } \\
\text { society for people with psychiatric } \\
\text { disabilities (Hutchinson et al., 2006) }\end{array}$ \\
\hline & \multicolumn{2}{|c|}{ Mental Resilience System } \\
\hline II. Internal Layers/Levels & $\begin{array}{l}\text { Natural (subject-related factors and } \\
\text { experience, temperament or } \\
\text { phenotype constructs) }\end{array}$ & Artificial (received from society) \\
\hline $\begin{array}{l}\text { 1. Nonspecific to adversity } \\
\text { barriers }{ }^{1}\end{array}$ & $\begin{array}{l}\text { Phenotype advantages related to } \\
\text { stress reactivity and modulated by } \\
\text { hormonal, autonomic and central } \\
\text { neurotransmitter balance (Young \& } \\
\text { Altemus, 2004; Davydov et al., } 2007 \\
\text { and 2010; Feder et al., 2009) }\end{array}$ & $\begin{array}{l}\text { Global mental health 'fortification' } \\
\text { with vitamin enrichment of food in } \\
\text { national nutrition programs (Alpert et } \\
\text { al., 2000) }\end{array}$ \\
\hline
\end{tabular}

2. Adaptive or specific to
adversity/pathogen barriers

Imprinting and implicit learning in Externally imposed regulation of a) Passive barrier after resilience infants (Schore, 2001) transfer $^{3}$ emotions and behaviours or modulation of emotion primarily through the efforts of others (Eisenberg \& Spinrad, 2004)

Epigenetic mechanisms of acquiring Cognitive reappraisals for being able to b) Active (acquired) barrier after stress responsiveness (Feder et al., adversity presentation ${ }^{4}$ 2009)

regulate emotion oneself (selfregulation of emotions) (Schaal et al., 2009)

\section{${ }^{1,2,3,4}$ Idem (see Table 1)}

